\title{
Influence of strain rate on subsolvus dynamic and post- dynamic recrystallization kinetics of Inconel 718
}

\author{
A. Nicolaÿ ${ }^{1,2 *}$, G. Fiorucci ${ }^{1}$, J.M. Franchet ${ }^{2}$, J. Cormier $^{3}$, N. Bozzolo ${ }^{1}$ \\ ${ }^{1}$ MINES ParisTech, PSL - Research University, CEMEF - Centre de mise en forme des matériaux, \\ Sophia-Antipolis, France \\ ${ }^{2}$ Safran SA, SafranTech - Materials \& Process Department, Magny-Les-Hameaux Cedex, France \\ ${ }^{3}$ Institut Pprime - Université de Poitiers - ENSMA, Physics and Mechanics of Materials Department, \\ Chasseneuil, France \\ * Correspondence: alexis.nicolay@ mines-paristech.fr / +33 493957555
}

Key words: Inconel 718; processing; dynamic recrystallization; post-dynamic recrystallization; strain rate.

\begin{abstract}
Influence of strain rate on dynamic and post-dynamic recrystallization kinetics of Inconel 718 is investigated by performing hot compression tests at constant strain rate in the range $[0.001 ; 1] s^{-1}$ in the $\delta$-subsolvus domain, with or without post-deformation holding at the deformation temperature. Dynamically and post-dynamically recrystallized grains are distinguished based on their internal misorientations, using EBSD data with enhanced angular resolution. For the applied deformation conditions $\left(T=980^{\circ} \mathrm{C}\right.$ and $\left.\varepsilon=0.7\right)$, dynamic recrystallization is inhibited at $\dot{\varepsilon}>0.1 \mathrm{~s}^{-1}$. On the other hand, very fast post-dynamic recrystallization is promoted by high strain rates, with characteristic times which can be as short as few seconds to achieve full recrystallization. Most of previous works on the effect of strain rate on dynamic recrystallization kinetics were done by quenching samples right after deformation, without discriminating dynamically and post-dynamically recrystallized grains. Those works led to the conclusion that increasing strain rate beyond a critical value leads to an increase in dynamic recrystallization kinetics. Experimental quenching delays cannot be shorter that few seconds, which is shown here to be sufficient to get a significant increase in recrystallized fraction by post-dynamic mechanisms. Based on the present work, postdynamic evolutions are actually very likely to be responsible for the apparent increase in dynamic recrystallization kinetics at high strain rates which has often been reported previously.
\end{abstract}

\section{Introduction}

Due to their good mechanical properties at high temperature, polycrystalline nickelbased superalloys are widely used in the hottest parts of aircraft engines, notably for turbine disks. These parts are generally obtained by complex forging routes including hot deformation and heating or annealing steps. Among all nickel-based superalloys, Inconel 718 achieves a good compromise between cost and performances and is still the most employed alloy for making turbine disks; it represents approximately one third of the weight of an aircraft engine [1]. For such a demanding application, microstructure and especially grain size must be precisely controlled, and this can only be done by controlling recrystallization mechanisms and kinetics and their dependence to thermomechanical conditions. 
During hot deformation of nickel-based superalloys, the dislocation density rises driven by strain hardening in the early stages of deformation. Once the dislocation density reaches a level high enough, discontinuous dynamic recrystallization (DDRX) can be triggered and then progresses in the microstructure with kinetics dependant on thermomechanical conditions [2-11]. This leads to a macroscopic softening of the alloy possibly leading to a drop in the flow stress [12-14]. Such a behavior is not specific to nickelbased superalloys. More generally, low to medium stacking fault energy $\left(\gamma_{S F E}\right)$ alloys are prone to discontinuous dynamic recrystallization [15-21] when deformed at high temperature. If the material is maintained at high temperature after deformation, for example between two forging steps or during the necessarily slow cooling of massive industrial pieces, microstructure keeps evolving. Post-dynamic recrystallization (PDRX) may then also occur, the kinetics of which notably depend on the thermomechanical conditions of the prior deformation [22-25], but also on the dynamically recrystallized fraction [26].

Static recrystallization (SRX) and meta-dynamic recrystallization (MDRX) are two different recrystallization mechanisms which can contribute to PDRX. SRX consists in both nucleation and growth of new grains after the end of deformation. MDRX only consists in the growth of DRX grain nuclei. In the following, the definition of MDRX will be extended to cover also the growth of DRX grains and not only of DRX grain nuclei. The growth of both SRX and MDRX grains is driven by the difference in stored energy (i.e. dislocation density) between the recrystallized grains and the deformed matrix around.

Contrary to PDRX grains which grow after deformation, dynamically recrystallized (DRX) grains appear and grow during deformation. As a direct consequence, DDRX grains are more strain hardened than PDRX grains. DRX and PDRX microstructures may thus lead to different mechanical properties. It is therefore of utmost importance to precisely describe DRX and PDRX kinetics and their dependence on thermomechanical conditions. The present paper addresses the influence of strain rate on those kinetics.

Dynamic recrystallization of Inconel 718 has been widely studied in the literature $[2-4,22,24,25,27-33]$, but only a few works were dedicated to the influence of strain rate, especially at high strain rates (typically $\dot{\varepsilon} \geq 0.1 s^{-1}$ ). Even if it is difficult to directly compare results reported in the literature since different thermomechanical parameters were used by the different authors, a general feature in DRX kinetics as a function of strain rate is massively reported in the literature and schematized on Figure 1. The reported trend is a decrease in DRX fraction (achieved at a given strain level) with increasing strain rate, up to a critical strain rate value beyond which the DRX fraction starts increasing again. Such a behaviour as a function of strain rate was reported not only for Inconel 718 [31-33] but also for other nickel-based superalloys [34-38], as well as for other types of alloys [39-41]. The decrease in DRX volume fraction when increasing strain rate in the low strain rate range is attributed to the shorter and shorter time available for the grains to nucleate and grow. The increase in DRX fraction above the "critical" strain rate is explained in the literature by the coupled effect of temperature increase (due to self-heating) and increased stored energy (due to higher strain rate) that boosts the driving force for DRX. In opposition with the trend shown in Figure 1, a few papers nevertheless report that the DRX fraction monotonously decreases with increasing strain rate, especially in Inconel 718 [4, 22]. In particular, in [4], Wang et al. did not observe any DRX fraction increase when increasing the strain rate up to $\dot{\varepsilon}=0.1 \mathrm{~s}^{-1}$ at $T=1000^{\circ} \mathrm{C}$ and for a final strain $\varepsilon=0.5$. In addition, in [22], Guest et al. report a similar trend as Wang et al. [4] with compression tests performed at $T=980^{\circ} \mathrm{C}$ and a strain rate varying up to $\dot{\varepsilon}=1.1 \mathrm{~s}^{-1}$. However, they achieve in this study a DRX kinetics 
similar to the one reported in Figure 1 when deformation temperature is switched to $T=$ $1040^{\circ} \mathrm{C}$. But again, the comparison between all these studies is really difficult because of the diversity of initial microstructures, applied thermomechanical parameters and deformation modes which are determinant for microstructural evolutions.

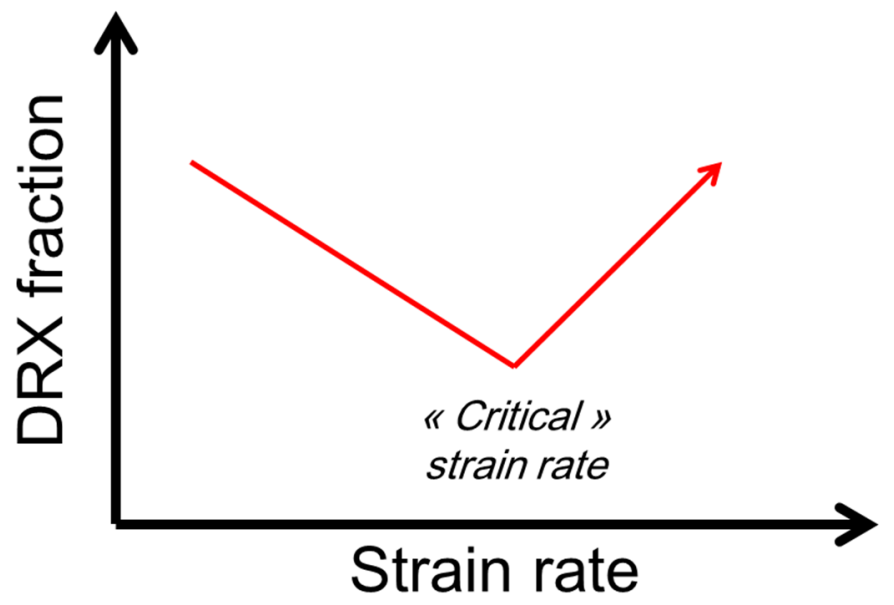

Figure 1: Scheme of the trend massively reported in the literature [31-41] for the influence of strain rate on DRX kinetics (DRX fraction achieved for a given strain level at a given nominal temperature as a function of strain rate)

In the present paper, the influence of strain rate on both DRX and PDRX kinetics is investigated with particular attention paid to the high strain rate domain $\left(\dot{\varepsilon} \geq 0.1 s^{-1}\right)$. For that purpose, DRX fraction was evaluated based on a new approach for the distinction between DRX and PDRX grains, based on their internal misorientations, using EBSD data with enhanced angular resolution. that is described in [42]. This leads to results which contradict the classical trend of DRX kinetics massively reported in the literature and schematized on Figure 1, and partly supports the results of [4, 22].

\section{Material and experimental procedures}

In order to mimic forging conditions, compression tests were performed on cylindrical specimens $(\phi 8 \mathrm{~mm} \times 12 \mathrm{~mm})$ taken at mid-radius of a $200 \mathrm{~mm}$ diameter billet of Inconel 718 whose composition is given in table $\mathbf{1}$.

\begin{tabular}{llllllll}
\hline Elements & $\mathrm{Ni}$ & $\mathrm{Cr}$ & $\mathrm{Mo}$ & $\mathrm{Nb}$ & $\mathrm{Al}$ & $\mathrm{Ti}$ & $\mathrm{Fe}$ \\
\hline Weight \% & $\mathrm{Bal}$. & 17.9 & 2.9 & 5.4 & 0.5 & 1.0 & 18.3
\end{tabular}

Table 1: Chemical composition of the Inconel 718 billet used in this work 
a)

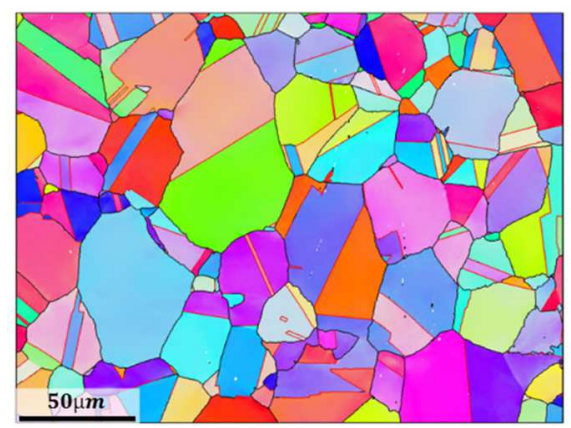

c)

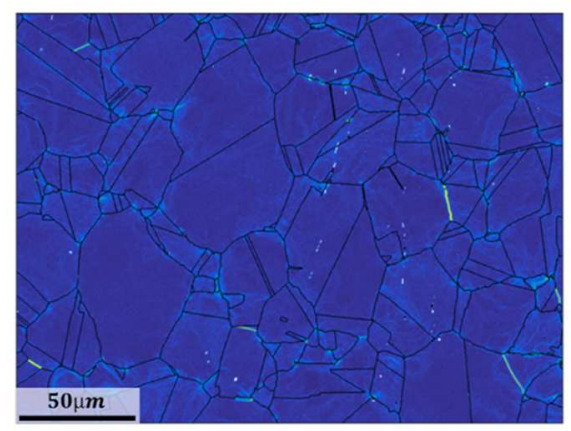

b)
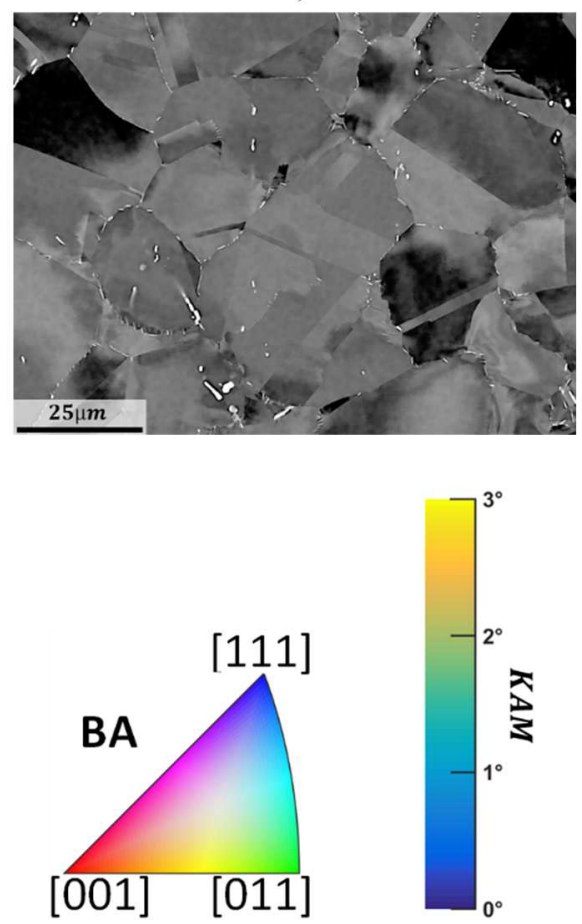

Figure 2: Microstructure just before compression (later on called initial microstructure). a) Orientation map obtained by conventional EBSD mapping $(0.2 \mu \mathrm{m}$ step size and 99\% indexing rate. Grain boundaries (>10 $0^{\circ}$ disorientation) are plotted black and twin boundaries $\left(60^{\circ}<111>\right.$ with a tolerance of $\left.2^{\circ}\right)$ red. b) Backscattered electron image highlighting $\delta$ phase in white. c) Kernel average misorientation (KAM) map, same area as a) with grain and twin boundaries plotted black.

Before compression, samples were heated and then maintained at the deformation temperature $T=980^{\circ} \mathrm{C}$ (below the $\delta$ solvus temperature) for 5 minutes for the sake of temperature homogenization. The microstructure obtained after such holding immediately followed by water quenching (identified by the yellow diamond on Figure 3) is shown on Figure 2. In the following, it will be referred to as the "initial microstructure" for discussing the changes occurring during and after hot-deformation. The initial grain size (defined as the mean equivalent circle diameter of the grains detected based on a $10^{\circ}$ misorientation angle threshold and ignoring twin boundaries) is $\overline{\emptyset_{e q}} \approx 18 \mu \mathrm{m}$. The initial $\delta$ phase volume fraction was estimated to be $f_{\delta} \approx 0.5 \%$ by grey level thresholding of backscattered electron images. After the 5 minutes holding, specimens are deformed at $T=980{ }^{\circ} \mathrm{C}$ and a strain rate in the range $\left[10^{-3} ; 1\right] s^{-1}$ up to a macroscopic strain $\varepsilon=0.7$, using a MTS 250 machine equipped with a resistive furnace. The lubrication at the sample/tool interface was done with graphite foils. The actual strain field in the compressed samples, obtained by thermomechanical FE simulation, is shown on Figure 3. As schematized on Figure 3, specimens were either water quenched right after compression for the characterization of dynamic evolutions, or they were maintained for different times at the deformation temperature before being water quenched for the characterization of post-dynamic evolutions. One must keep in mind that i) due to selfheating the sample temperature is likely to increase during deformation (especially for highest strain rates) contrary to the simplified scheme of Figure 3, and ii) immediate quenching after deformation is not possible experimentally; the effective minimum delay was measured to be between 2 and 3 seconds based on recorded videos of the test endings. Such a short quenching 
delay could be reached thanks to the furnace being mounted on pneumatic cylinders, which allows a vertical translation along the tools. The furnace can thus be removed rapidly at the end of the compression. In addition, compression experiments were conducted by two people. One person launches the test using an external command (a switch), and brings the quenching tank near to the tools, while the other person is only focused on pushing the sample in the quenching tank as fast as possible when the furnace has moved up.

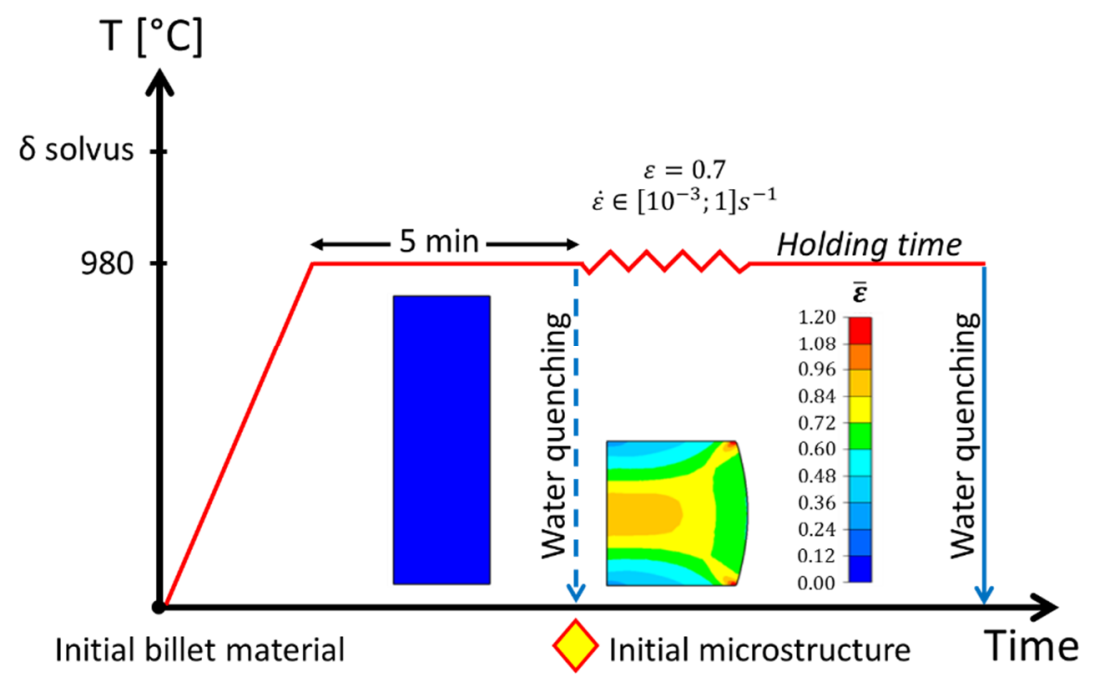

Figure 3: Thermomechanical paths for hot compression tests. The yellow diamond corresponds to the thermomechanical path applied to assess the so-called initial microstructure shown in Figure 2.

After compression tests, specimens were cut in two halves along the longitudinal direction of the cylinder (i.e. parallel to the billet axis BA) for metallographic preparation. Microstructure was then analysed by means of scanning electron microscopy (SEM) and electron backscattered diffraction (EBSD) at the center, where the local equivalent strain reaches $\bar{\varepsilon} \approx 0.9$ for a macroscopic strain $\varepsilon \approx 0.7$. In order to achieve a surface quality suitable for EBSD analyses, the surface was first pre-polished using $\mathrm{SiC}$ abrasive papers (down to a SiC granulometry of $5 \mu \mathrm{m}$ ), then mechanically polished using $3 \mu \mathrm{m}$ and then $1 \mu \mathrm{m}$ diamond suspensions, and finally electropolished for 5 seconds at $35 \mathrm{~V}$ with a solution of $10 \%$ perchloric acid in ethanol at $-5^{\circ} \mathrm{C}$. EBSD maps $(1100 \times 825$ points with a step size of $0.2 \mu \mathrm{m})$ were acquired using a Carl Zeiss Supra 40 field emission gun scanning electron microscope (FEGSEM) equipped with a Bruker Quantax system comprising an EBSD e-Flash ${ }^{\text {HR }}$ detector and the Esprit 2.1 software package.

Post-processing of EBSD data was conducted using the MTEX toolbox in the Matlab software package [43]. For studying recrystallization, two intragranular misorientation parameters are used since they vary with the dislocation density [44, 45]: the Kernel Average Misorientation (KAM) that is a local property (one value per measurement point) and the Grain Average KAM (GAKAM) that is a grain property (one value per grain). The KAM value of a given point is equal to the average of the misorientation angles $\theta_{i j}$ between this point $\mathrm{i}$ and its $n$ neighbours $\mathrm{j}$ (equation 1). In this work, the first and the second neighbours were considered for calculating the KAM values. The GAKAM value of a grain $k$ made of $\mathrm{N}$ points is defined as the average of the KAM values of all points in this grain (equation 2). Using conventional EBSD with a typical angular resolution in the range of $0.5^{\circ}, \mathrm{DRX}$ and 
PDRX grains cannot be separated based on intragranular misorientation criteria (see Figure 4a and detailed in [42]), but the overall recrystallized fraction can be measured.

$$
\begin{gathered}
K A M_{i}=\frac{1}{n} \sum_{j=1}^{n} \theta_{i j} \\
G A K A M_{k}=\frac{1}{N} \sum_{k=1}^{N} \frac{1}{n} \sum_{j=1}^{n} \theta_{i j}
\end{gathered}
$$

Recrystallized (including DRX and PDRX) and non-recrystallized grain populations can indeed be quantified using the GAKAM distribution, if necessary, coupled with a grain size criterion given that recrystallization leads to significant grain refinement. A first GAKAM threshold is set for the separation of these two populations of grains. If some grains remain misclassified (this evaluation is visual and based on KAM maps), this first threshold value is further refined. The recrystallized fraction is estimated as being the surface area fraction occupied by the recrystallized grains detected that way.

Studying DRX kinetics as a function of strain rate requires distinguishing DRX and PDRX grains that may be coexisting in the analysed microstructures. Recently, the authors have shown that it was actually possible to reliably identify DRX and PDRX grains via EBSD analysis, provided that the orientation measurement noise is low enough [42]. Filtering standard angular resolution EBSD data (whose standard measurement noise is around $0.5^{\circ}$ ) with the newly developed LLASS (Local Linear Adaptation of Smoothing Splines) filter by Seret et al. [45] was demonstrated to open the possibility of distinguishing, qualitatively and quantitatively, DRX grains from PDRX grains based only on the analysis of the GAKAM distribution of recrystallized grains (see Figure 4b). In the following, this new approach will be used for separating DRX and PDRX grains in samples immediately water quenched after deformation in order to determine as precisely as possible the DRX fraction that represents the starting point for post-dynamic evolutions. Then, for longer holding times after deformation at a given strain rate, the PDRX fraction will be obtained as the difference between the recrystallized fraction and the previously estimated DRX fraction. 
a)

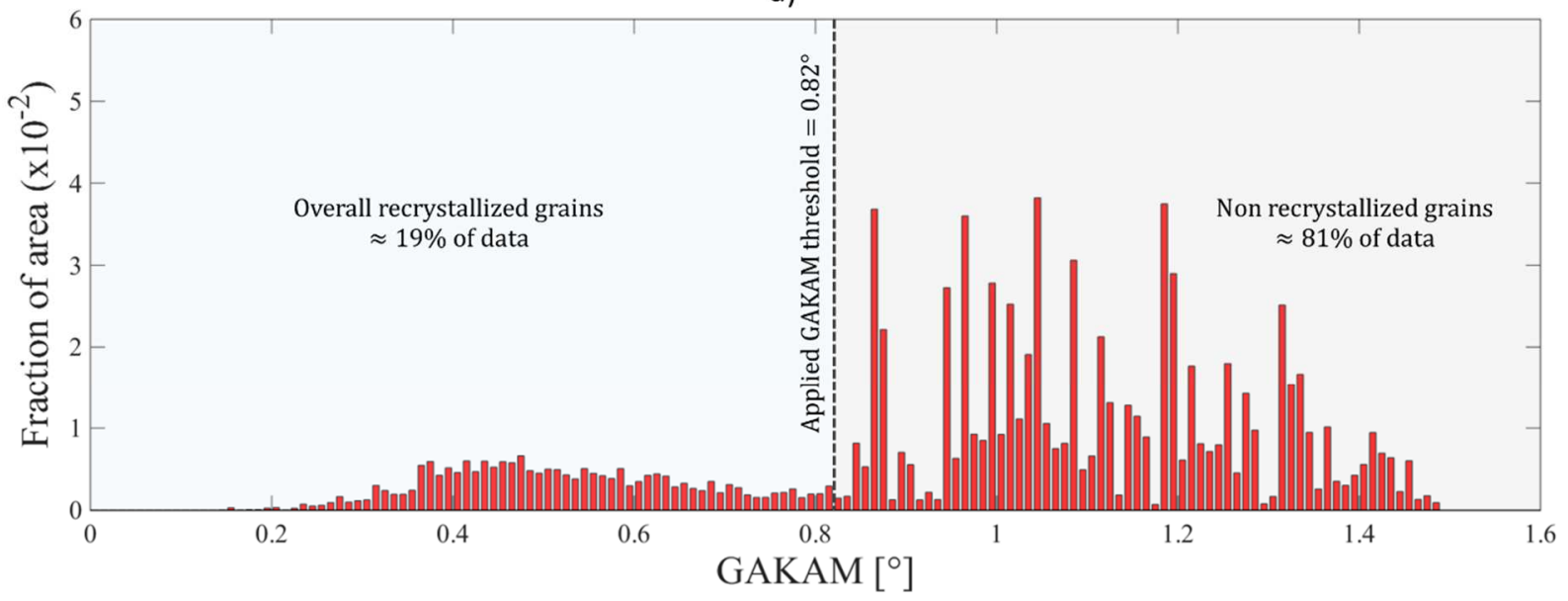

b)

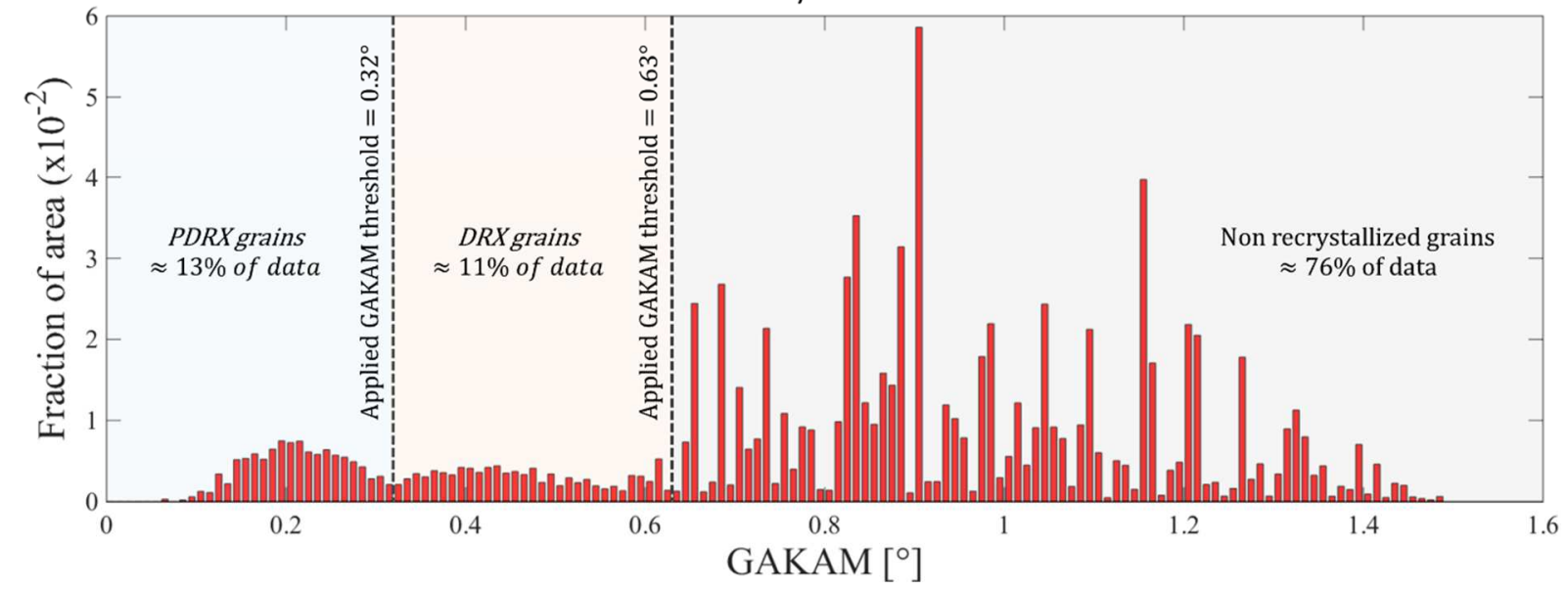

Figure 4: GAKAM distribution for the microstructure shown on Figure 5e containing non recrystallized grains, and both DRX and PDRX grains. GAKAM thresholds applied for the separation of grain populations are displayed. a) Distribution resulting from conventional EBSD data b) Distribution resulting from the same conventional EBSD data after noise reduction by the LLASS filter [45]. 


\section{Results and discussion}

\subsection{DRX kinetics assessed from samples water quenched right after deformation}

KAM maps of samples quenched right after deformation are shown on Figure 5 for different strain rates in the range $[0.001 ; 1] s^{-1}$. Based on the GAKAM distributions the global recrystallized fraction as well as the respective contributions of DRX and PDRX have been estimated as described in the previous section and illustrated on Figure 4. For all samples, DRX and PDRX grains identification is highlighted on the right column maps of Figure 5, each corresponding to a small area spotted by a white frame on the left column maps.

For each condition, a partially recrystallized microstructure is obtained. The deformed grains initially present in the starting microstructure can be easily identified. They are generally bigger than recrystallized grains and contain substructures which are well defined after LLASS filtering of EBSD data. The strain hardening level (varying as intragranular misorientations) in deformed grains increases with increasing strain rate when $\dot{\varepsilon} \leq 0.1 \mathrm{~s}^{-1}$ and seems then to decrease for higher strain rate.

When $\dot{\varepsilon} \leq 0.1 \mathrm{~s}^{-1}$ classical discontinuous DRX is detected on these partially recrystallized microstructures. New DRX grains nucleate and grow at former grain boundaries leading to the so-called necklace microstructures. However, lower and lower amounts of DRX grains are found in the microstructure when the strain rate is increasing. Even if samples used in Figure 5 have been quenched in only few seconds, PDRX is detected and its fraction increases with increasing strain rate. Although efforts have been made to reduce the quenching delay to the minimum achievable $(\Delta t<2 s)$ for samples deformed at $\dot{\varepsilon}=0.1 s^{-1}$ and $\dot{\varepsilon}=1 s^{-1}$, the amount of detected PDRX grains is quite high.

Figure 6 summarizes the quantitative results obtained from the maps of Figure 5. On Figure 6, the evolution of the total recrystallized fraction is reported with black squares connected by a black solid line and the associated DRX fraction with black squares connected by a black dashed line, as a function of strain rate. This way, the DRX and PDRX contributions to the total recrystallized fraction can be visualized. The dependence of DRX kinetics on strain rate is monotonously decreasing with increasing strain rate, which is not consistent with what is massively reported in the literature [31-41] and schematized on Figure 1 excepted in the work by Guest et al. [22]. They were the only ones to have reported a DRX kinetics similar to the one obtained in this study using close thermomechanical conditions to the best knowledge of the present authors. The DRX is found here to be inhibited at high strain rates. For the conditions applied in this work $\left(T=980^{\circ} \mathrm{C}\right.$ and $\left.\varepsilon=0.7\right)$, DRX is inhibited at $\dot{\varepsilon}>0.1 \mathrm{~s}^{-1}$. However, it is important to notice that the strain rate beyond which the DRX is inhibited is likely to depend on the other deformation conditions (temperature and strain level). Results of Figure 5 and $\mathbf{6}$ thus suggest that the time parameter is of a great importance for dynamic evolutions. Indeed, even if the reasons given in the literature to explain that high strain rate increases the driving force for DRX could be relevant, actual results suggest that the deformation time which is determined by the strain rate is a key parameter for the progress of DRX. 
In addition, it can be mentioned here that, for samples on which a significant DRX fraction is detected (i.e. for samples deformed at $\dot{\varepsilon} \leq 0.1 \mathrm{~s}^{-1}$ ), the measured DRX grain size (calculated as the mean equivalent circle diameter of the DRX grains detected and ignoring twin boundaries ) for samples deformed at $\dot{\varepsilon}=0.001 \mathrm{~s}^{-1}, \dot{\varepsilon}=0.01 \mathrm{~s}^{-1}$ and $\dot{\varepsilon}=0.1 \mathrm{~s}^{-1}$ are respectively $3.4 \mu \mathrm{m}, 2.6 \mu \mathrm{m}$ and $2.2 \mu \mathrm{m}$. The well-established effect of strain rate on DRX grain size is thus confirmed; higher strain rate leading to finer DRX grains.

Contrary to the DRX behaviour, the PDRX contribution to the global recrystallized fraction is found to increase with increasing strain rate in those samples quenched as quickly as possible after deformation. For low to medium strain rates (typically here for $0.001 \mathrm{~s}^{-1} \leq$ $\dot{\varepsilon} \leq 0.01 \mathrm{~s}^{-1}$ ) the PDRX contribution remains quite low even though the quenching delays was 5 to 6 seconds in those experiments, and the global recrystallized fraction evolution as a function of strain rate is mostly driven by the DRX kinetics. The increase in PDRX contribution comes to be very pronounced for the highest applied strain rates. It must be pointing out here that much attention has been paid to reducing the quenching delays as much as possible for those high strain rate experiments. At $\dot{\varepsilon}=1 s^{-1}$, PDRX actually massively operated during the quenching delay of only two seconds and leads to a pronounced increase in the global recrystallized fraction.

It is worth noticing that the evolution of the global recrystallized fraction with strain rate, encompassing both DRX and PDRX grains, is very similar to what has often been reported as the evolution of DRX kinetics in the literature.

The global recrystallized fraction estimated on samples quenched right after deformation is classically assimilated to the DRX fraction since fast quenching is supposed to freeze the microstructure of the end of deformation and thus to allow catching the result of dynamic evolutions only. However, instantaneous quenching is technically not possible, the experimental quenching delay cannot be much shorter than two seconds. As a consequence, very fast PDRX kinetics operating during the quenching delay after high strain rate deformation are very likely to explain the divergences between the DRX kinetics as a function of strain rate obtained here and those massively reported in the literature. The fact that PDRX could occur during the quenching after high strain rate deformation was actually suggested earlier by Zhou et al. [29] and was proposed as one possible explanation of the differences between their results and microstructural evolutions reported by Camus et al. in [46]. The same hypothesis was proposed more recently by Kienl et al. [47], also to justify the increase in the recrystallized fraction with increasing strain rate in ATI 718Plus ${ }^{\circledR}$ samples quenched after deformation. A deeper study of the PDRX kinetics dependence on strain rate will be carried out in section 2.3 in order to confirm this interpretation of the above-presented results. 
a)

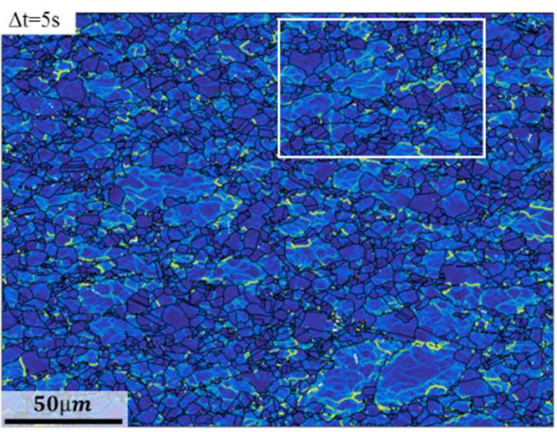

c)

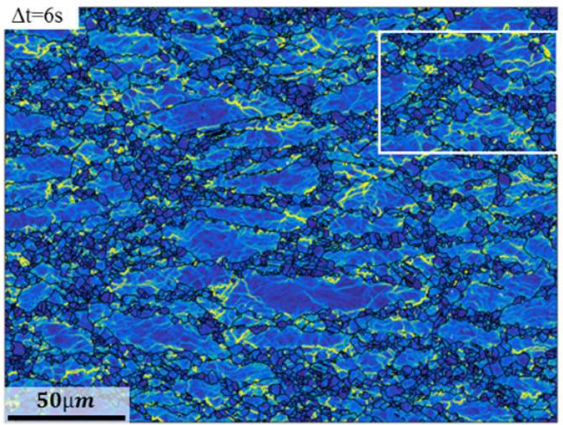

e)

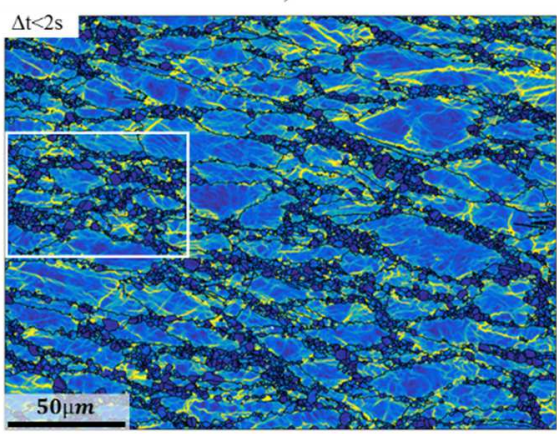

g)

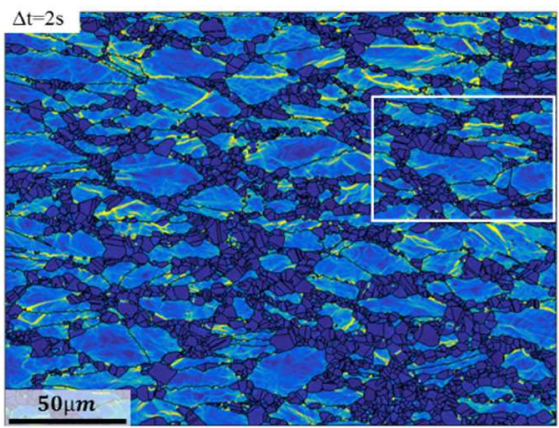

i)

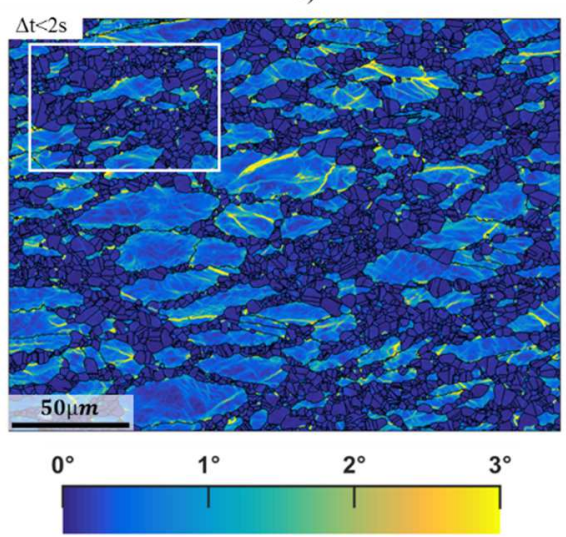

b)

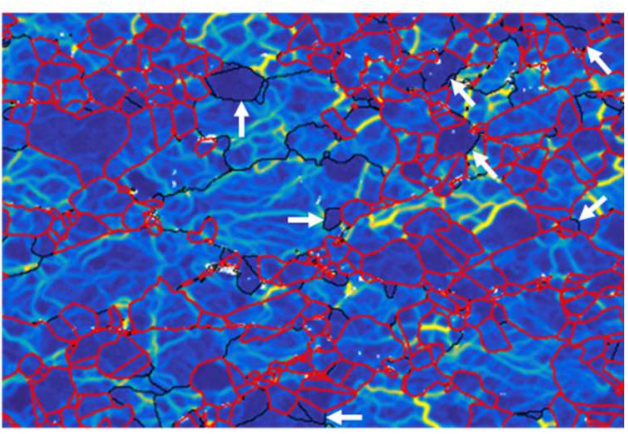

d)

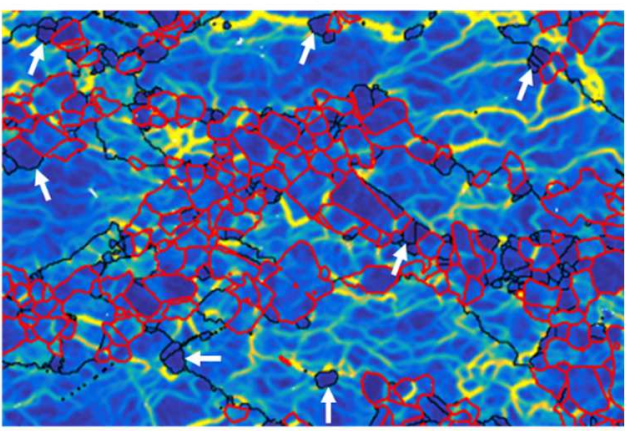

f)

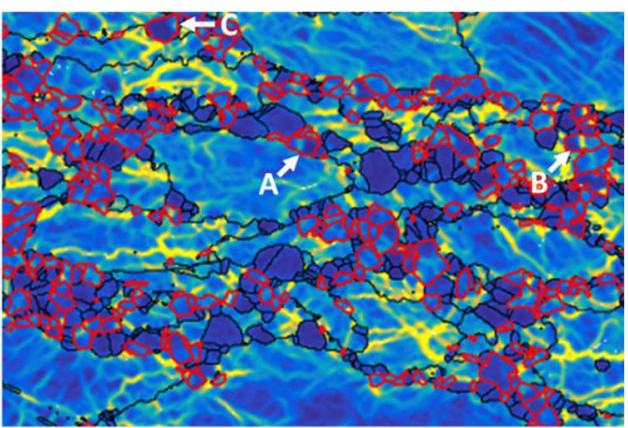

h)

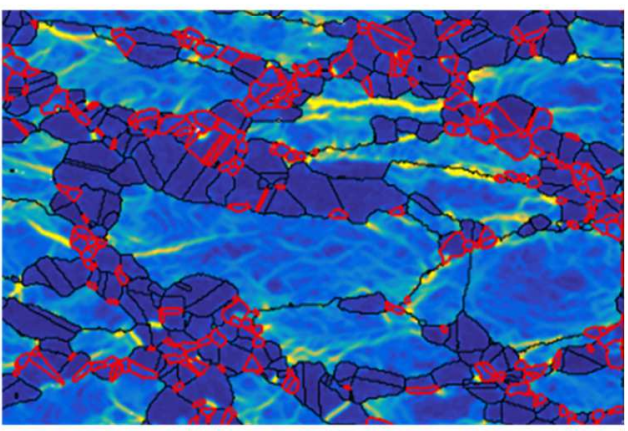

j)

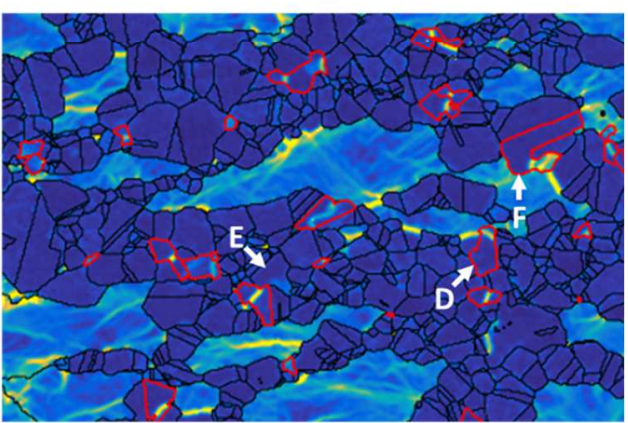


Figure 5: KAM maps of samples rapidly quenched after deformation to a macroscopic strain $\varepsilon=0.7$ at $T=980^{\circ} \mathrm{C}$ and for a strain rate of a), b) $\left.\left.\left.\left.\dot{\varepsilon}=0.001 \mathrm{~s}^{-1}, c\right), d\right) \dot{\varepsilon}=0.01 \mathrm{~s}^{-1}, e\right), f\right)$ $\left.\left.\dot{\varepsilon}=0.1 s^{-1}, g\right), h\right) \dot{\varepsilon}=0.5 s^{-1}$, and $\left.\left.i\right), j\right) \dot{\varepsilon}=1 s^{-1}$. On the right column, $b$ ), $\left.d\right), f$ ), $h$ ) and $j$ ) corresponds respectively to the area delimited by the white frame in a), c), e), g) and i) after the separation between DRX (surrounded in red) and PDRX grains after LLASS filtering of EBSD data [45]. For all those maps, the minimum effective indexing rate was $97.9 \%$ after removing data corresponding to grains of less than 4 points. Non-indexed points and points filtered out after this grain size criterion are ignored in the calculation of KAM and GAKAM parameters.

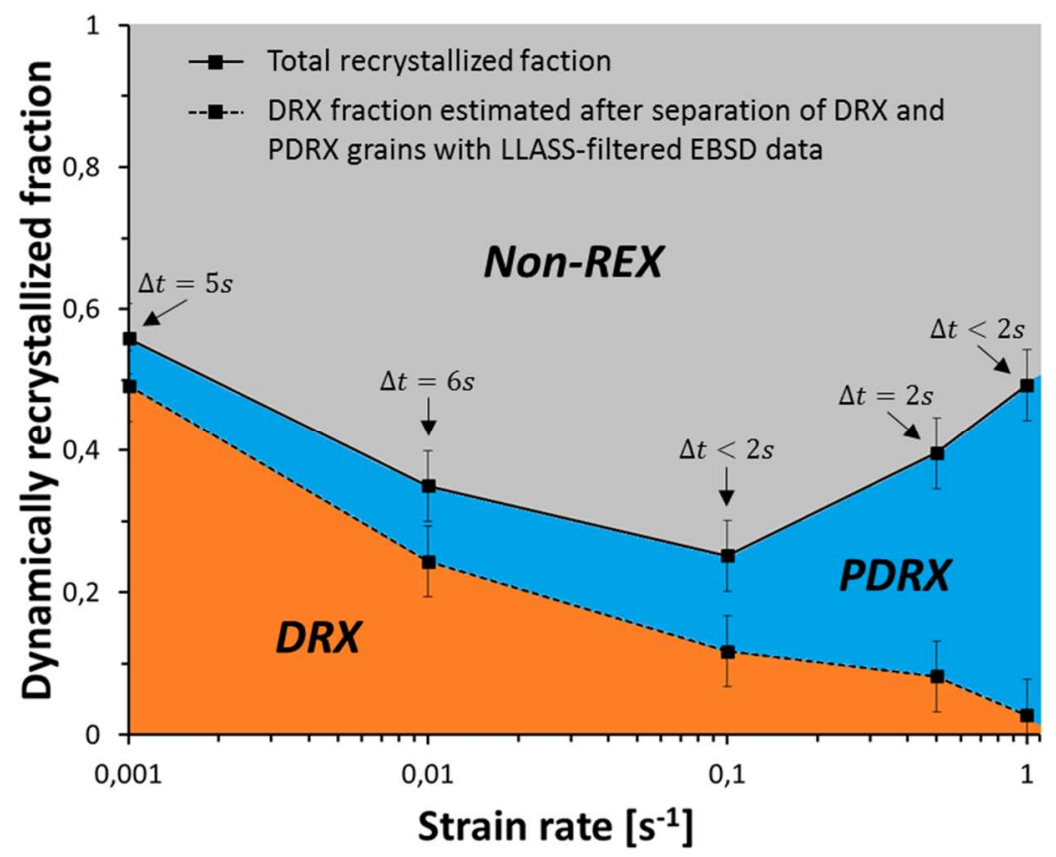

Figure 6: Estimation of DRX area fractions as a function of strain rate using the approach detailed in [42] for the separation between DRX and PDRX grain populations using the EBSD data shown in the left column of Figure 5. Samples were quenched as quickly as possible after deformation up to the macroscopic strain $\varepsilon \approx 0.7$ at $T=980^{\circ} \mathrm{C}$ and at $\dot{\varepsilon} \in[0.001 ; 1] s^{-1}$. The measured quenching delay $\Delta t$ is given for each sample.

\subsection{Analysis of the stress - strain curves}

The stress level $\sigma$ is directly linked to the mean dislocation density $\rho$ as expressed in the famous Taylor relationship [48] reminded in equation 3. As a consequence, strain-stress curves resulting from hot deformation of nickel-based superalloys are extensively used to discuss microstructural evolutions, especially the DRX behaviour. The flow curves of the performed compression tests are shown on Figure 7. Observations that can be done from these curves are consistent with those classically reported in literature for Nickel-based superalloys and other alloys submitted to DRX phenomena when deformed at high temperature. For each strain rate, a significant increase in stress level is observed in the early stages of deformation due to a fast increase in the mean dislocation density (i.e. strain hardening). Then, the strain hardening rate progressively decreases due to the occurrence of softening mechanisms (DRX and dynamic recovery to a lower extent) until the stress reaches 
a maximum value $\sigma_{p}$. Above this peak stress, the DRX fraction is high enough to counterbalance the effect of strain hardening on the macroscopic flow stress.

$G$ the shear modulus

$$
\sigma=\sigma_{0}+\alpha M G b \sqrt{\rho}
$$

$b$ the Burgers vector magnitude

$\alpha$ a constant (between 0.2 and 0.4 for metal alloys)

$M$ Taylor factor (around 3.1 for polycrystals)

$\sigma_{0}$ "dislocation free" yield stress

DRX initiation is usually estimated from the strain $\varepsilon_{p}$ reached at the peak stress $\sigma_{p}$. Actually, it has been shown many times in the literature that DRX is initiated at $\varepsilon$ slightly lower than $\varepsilon_{p}[12,17,29,49]$. As a result of low plastic strain, dislocation distribution within the microstructure is heterogeneous. Dislocations are preferentially accumulated at grain boundaries and triple junctions (dislocations pile-up) which serve as preferential nucleation sites for DRX grains, appearing thus before $\varepsilon$ reaches $\varepsilon_{p}$. On Figure 7, maximal stresses $\sigma_{p}$ are marked for each strain rate condition with red squares and are linked to each other with a dashed red line. It can be observed that $\sigma_{p}$ value increases when the strain rate is increasing which is consistent with results reported in the literature [2-4, 28-30, 33, 34]. Higher dislocation densities are thus reached when strain rate is increasing. This is basically explained by the fact that higher strain rate implies lower available time for dislocation annihilation. The peak strain $\varepsilon_{p}$ increases with increasing strain rate in the range $[0.001 ; 0.1] \mathrm{s}^{-1}$. This trend indicates that DRX is initiated at higher strain level when the strain rate is increased up to $\dot{\varepsilon}=0.1 s^{-1}$. However, when $\dot{\varepsilon}=1 s^{-1}, \varepsilon_{p}$ drops significantly whereas $\sigma_{p}$ (i.e. $\rho$ ) keeps increasing. This result would signify that at $\dot{\varepsilon}=1 s^{-1}$, the DRX is triggered in the very early stages of deformation $\left(\varepsilon_{p} \approx 0.15\right)$ compared to lower strain rate deformations, which is not consistent with the very low DRX fraction measured after $\varepsilon \approx 0.7$ (Figures 5 and 6). The higher dislocation density reached in this condition could be a good argument to justify that the driving force for DRX is increased and could intervenes earlier in the deformation. However, this interpretation of the plastic flow curve at $\dot{\varepsilon}=1 \mathrm{~s}^{-1}$ is inconsistent with the DRX kinetics established in section 2.1.

In order to explore what happens in the microstructure at $\varepsilon=\varepsilon_{p}$ for $\dot{\varepsilon}=1 \mathrm{~s}^{-1}$, an interrupted test was performed in the same thermomechanical conditions excepted that deformation was stopped at $\varepsilon \approx 0.35$ before fast water quenching. The corresponding KAM map of the as-quenched microstructure is shown on Figure 8. This complementary KAM map definitely proves that the peak stress in this strain rate condition cannot be associated with the DRX initiation. Indeed, whereas $\varepsilon>2 \varepsilon_{p}$, only relatively few recrystallized grains can be found in the deformed matrix and their low KAM value levels strongly suggest that those are more likely to be PDRX grains (see Figure 8). As a consequence, in such high strain rate conditions, the fast drop in stress level with increasing strain level above $\varepsilon_{p}$ is mostly attributed to a significant self-heating known to be promoted at high strain rates. As a consequence, taking into account results presented from Figure 5 to 8, it can thus be deduced 
that flow curves exploitation for discussing DRX initiation seems no longer adapted for $\dot{\varepsilon}>$ $0.1 s^{-1}$.

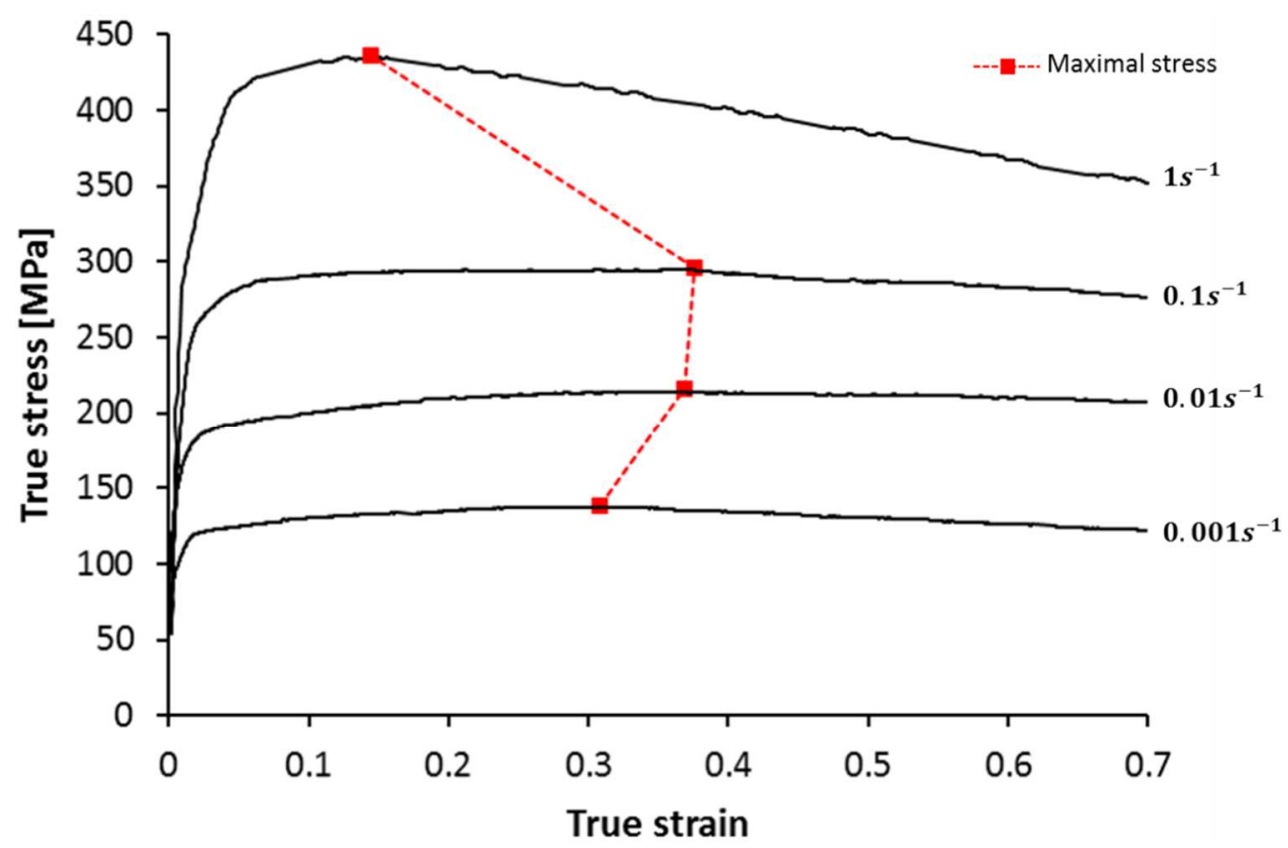

Figure 7: Stress - strain curves for samples deformed up to a macroscopic strain $\varepsilon \approx 0.7$ at $T=980^{\circ} \mathrm{C}$ and at different strain rates in $[0.001 ; 1] \mathrm{s}^{-1}$. The maximum stress values are indicated with a red square and are connected to each other with a dashed red line. 


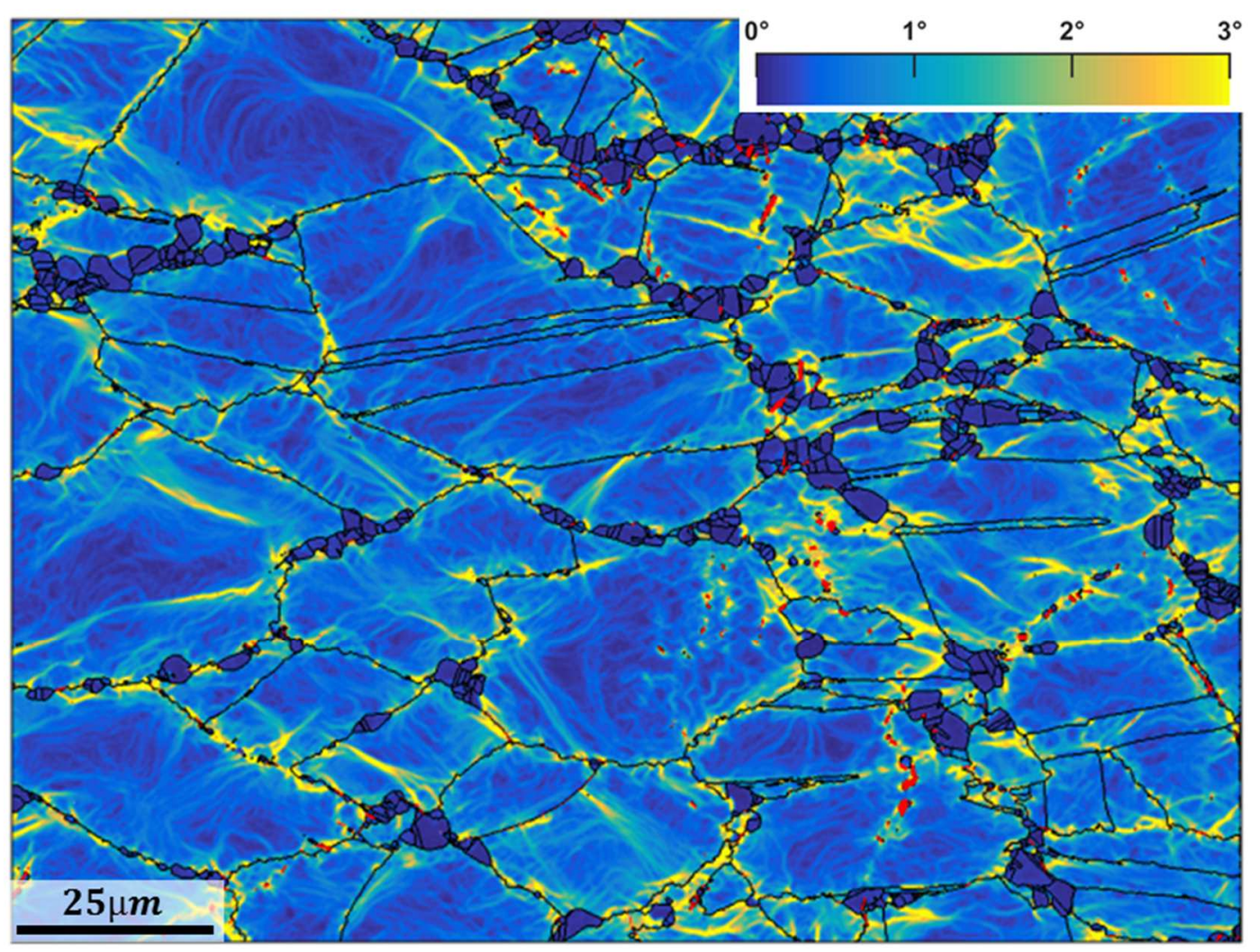

Figure 8: KAM map of a fast water quenched $(\Delta t<3 s)$ sample deformed up to a true strain $\varepsilon=0.35$ at $\dot{\varepsilon}=1 \mathrm{~s}^{-1}$ and at $\mathrm{T}=980^{\circ} \mathrm{C}$. Deformation conditions are the same as the ones used for Figure $5 \mathrm{~g}$ and $\mathbf{5 h}$, but here deformation has been stopped earlier, closer to the stress peak. Contrary to all the other EBSD data presented in this study, here the $\delta$ phase was also indexed, especially thanks to the fact that this EBSD analysis was performed with a smaller step size $(0.14 \mu \mathrm{m})$. $\delta$ phase particles are plotted in red.

\subsection{PDRX kinetics in samples with post-deformation holding}

KAM maps for samples deformed to $\varepsilon \approx 0.7$ at $\mathrm{T}=980^{\circ} \mathrm{C}$ and a strain rate in the range $[0.001 ; 1] \mathrm{s}^{-1}$ and then held for different times before quenching are shown on Figure 9. KAM maps of the left column (Figures 9a, 9d, 9g, and 9j) are those corresponding to the shortest holding times, already shown in Figures 5 and 6. As a general trend, Figure 9 shows that, independently of the strain rate influence, increasing the quenching delay after deformation allow PDRX to occur and expand in the microstructure, leading to significant increase in the global recrystallized fraction. PDRX evolutions have been quantified and plotted on Figure 10. Figure 10a shows the global recrystallized fraction corresponding to each map of Figure 9 as a function of strain rate and for the different performed holding times. The DRX volume fractions estimated in section 2.1 are also reminded on Figure 10a. In Figure 10b the same information is represented but PDRX kinetics are represented in a time scale for each strain rate.

As general trends, PDRX appears to be rather fast and to be faster and faster as strain rate is increased. These results are consistent with those reported in the literature for studies addressing the impact of strain rate on PDRX [23, 24, 29]. As a consequence, what was suggested previously from Figure 5 and 6 can thus be confirmed; high strain rates drastically accelerate post-dynamic evolutions. After deformation at $\dot{\varepsilon}=1 s^{-1}$, whereas the DRX 
fraction that represents the starting point for the PDRX kinetics is very low, the PDRX has invaded approximately $80 \%$ of the microstructure within only $8 \mathrm{~s}$. In such deformation conditions, it is thus clear that the characteristic time for PDRX is of the same order of magnitude or smaller than the shortest achievable quenching delay which has been measured below 2 seconds. In the study of Guest et al. [22], the measured quenching delay was very low $(<1 \mathrm{~s})$ that could explain why they did not observe any increase in DRX fraction at $\dot{\varepsilon} \approx 1 s^{-1}$ for $T=980^{\circ} \mathrm{C}$ and $\varepsilon=0.7$. In this case, a quenching delay lower than $1 \mathrm{~s}$ seems thus sufficient to limit the PDRX contribution on the global recrystallized fraction estimated on samples quenched right after deformation. However, it looks no longer to be the case when the deformation temperature is increased to $1040^{\circ} \mathrm{C}$ since, in this condition, they obtained a DRX kinetics similar to the one generally reported and presented on Figure 1.

The observed acceleration of PDRX kinetics with increasing strain rate in the range $[0.001 ; 0.1] \mathrm{s}^{-1}$ can be attributed to the coupled effect of a possible temperature increase and increased stored energy that boosts the driving force for PDRX. Indeed, on the one hand, it is well-known and many times highlighted in literature [33-35, 49, 50] that increasing the strain rate leads to a rise in self-heating. On the other hand, it is generally assumed that, at a given temperature and for a given strain level, the dislocation density increases with increasing strain rate. This is actually what is found here for deformation at strain rates in the range $[0.001 ; 0.1] \mathrm{s}^{-1}$ since the mean GAKAM values of the remaining deformed grains, reported in Table 2 for samples quenched right after deformation, increase with increasing strain rate. Results reported in Table 2 suggest that this is not true any longer for strain rates higher than $\dot{\varepsilon}=0.1 \mathrm{~s}^{-1}$. In order to ensure that those conclusions drawn from Table 2 are not biased by the fact that the recrystallized grains consume the more strain hardened areas first, the GAKAM values of the remaining deformed grains are compared for microstructures with similar recrystallized volume fractions in Table 3. Considering the results presented in Table $\mathbf{3}$, the previous conclusions drawn from Table 2 are actually confirmed: GAKAM values, and thus dislocation densities in non-recrystallized grains, increase with increasing strain rate up to $\dot{\varepsilon}=0.1 \mathrm{~s}^{-1}$ and then decreases for $\dot{\varepsilon}>0.1 \mathrm{~s}^{-1}$. This decrease in the work-hardening of the grains deformed at high strain rates is likely to be related to self-heating and a significant increase in temperature. As a consequence, the acceleration of PDRX kinetics after deformation at high strain rates is more likely to be due to the temperature increase than to an increase in dislocation density. 
a)

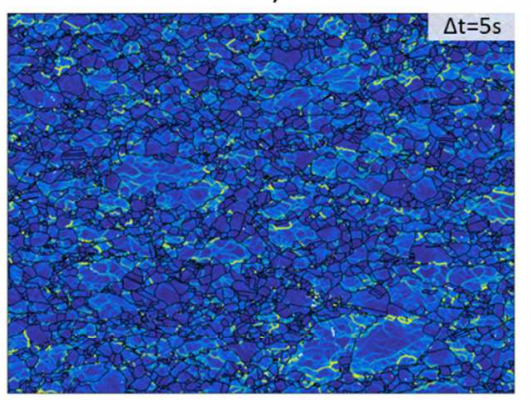

d)

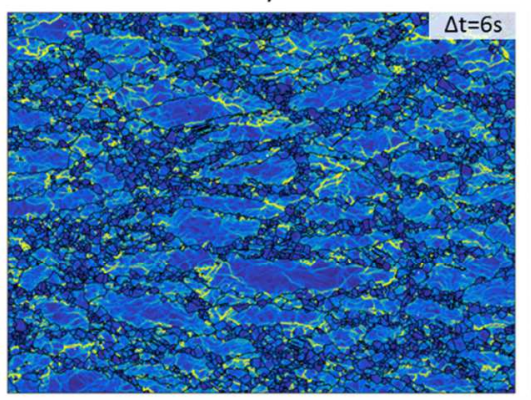

g)

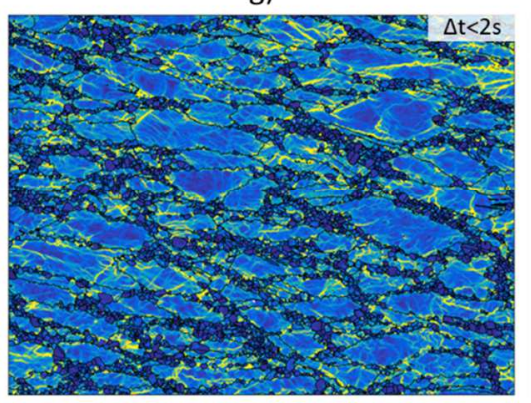

j)

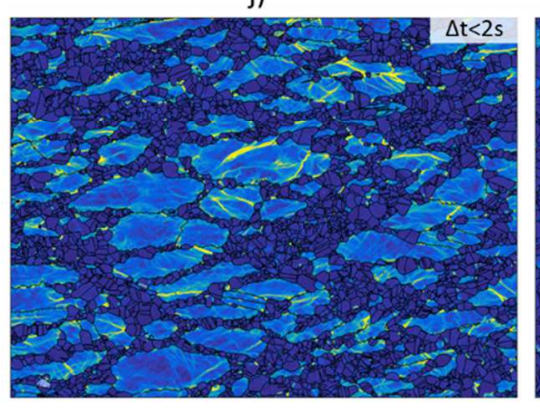

$1^{\circ}$

$3^{\circ}$ b)

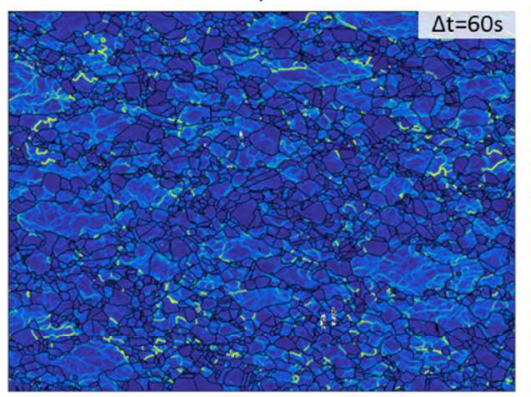

e)

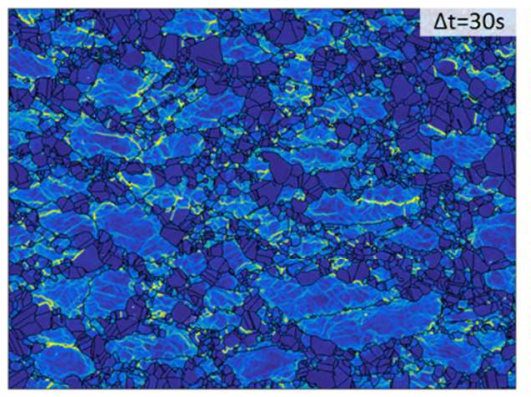

h)

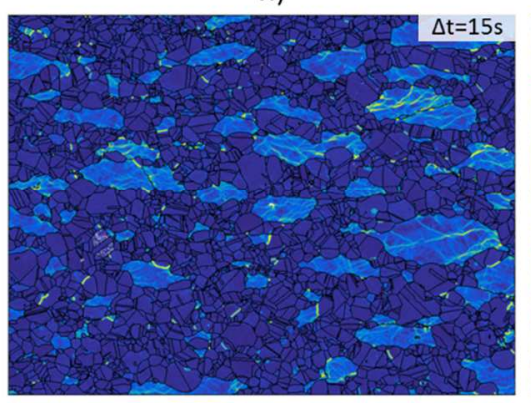

k)

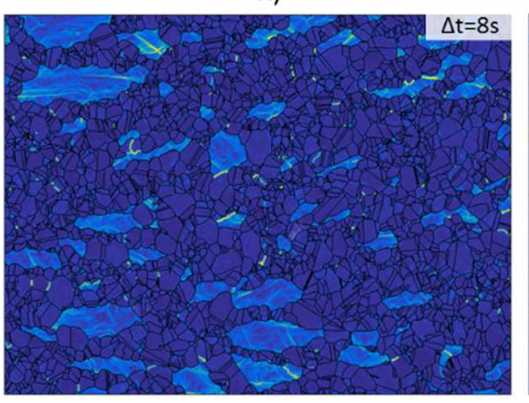

c)

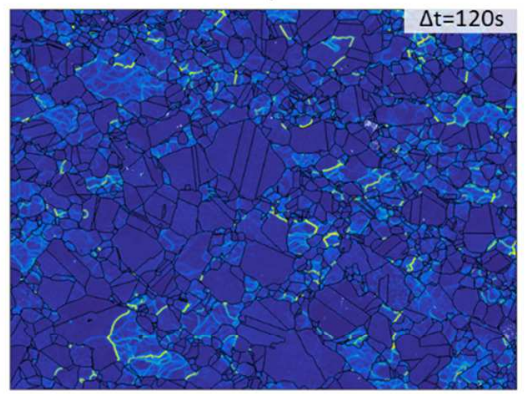

f)

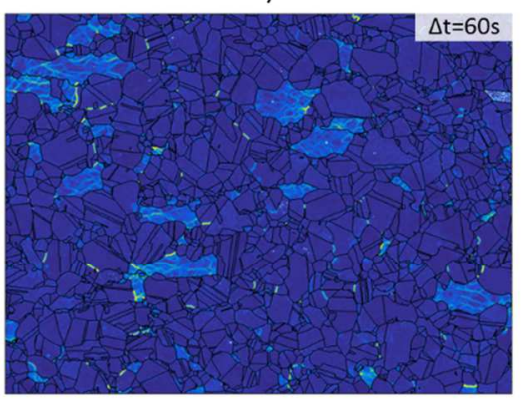

i)

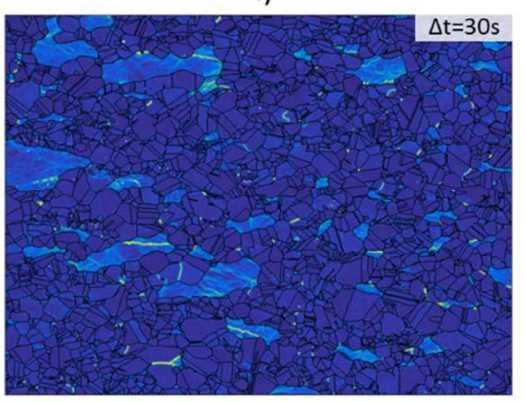

I)

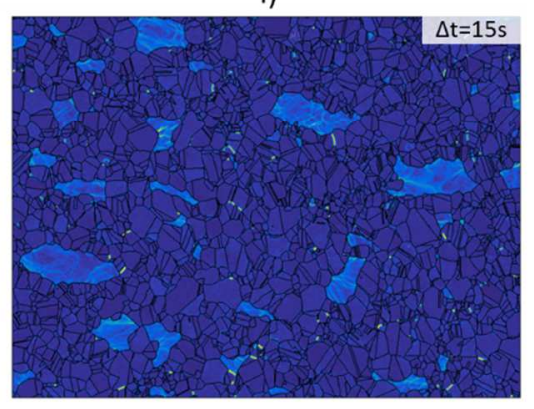

$50 \mu m$

Figure 9: KAM maps of samples deformed up to the macroscopic strain $\varepsilon \approx 0.7$ at $T=$ $980^{\circ} \mathrm{C}$ and at a), b), c) $\left.\left.\left.\left.\dot{\varepsilon}=0.001 \mathrm{~s}^{-1}, d\right), e\right), f\right) \dot{\varepsilon}=0.01 \mathrm{~s}^{-1}, g\right), h$ ), i) $\dot{\varepsilon}=0.1 \mathrm{~s}^{-1}, j$ ), $k$ ), l) $\dot{\varepsilon}=1 s^{-1}$. Grain and twin boundaries $\left(>10^{\circ}\right)$ are plotted in black, and corresponding measured holding times before quenching $\Delta$ t are indicated on each map. 
a)

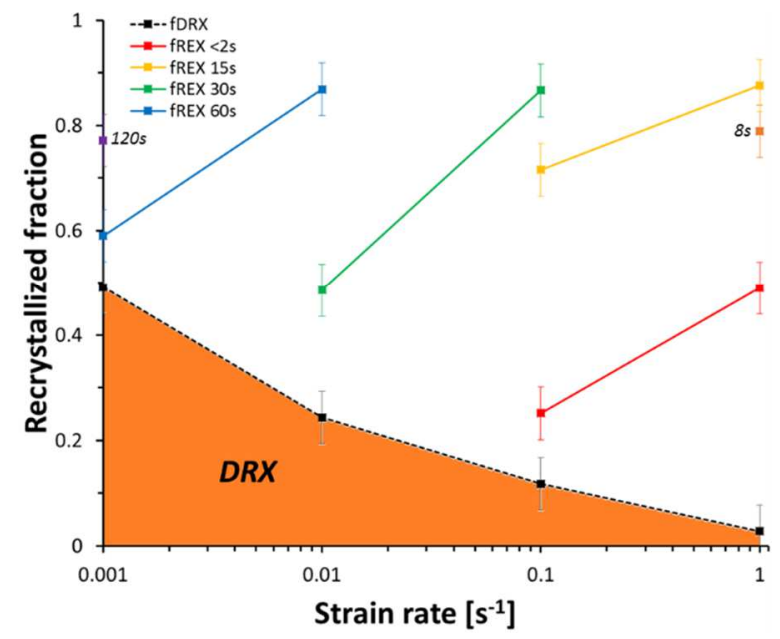

b)

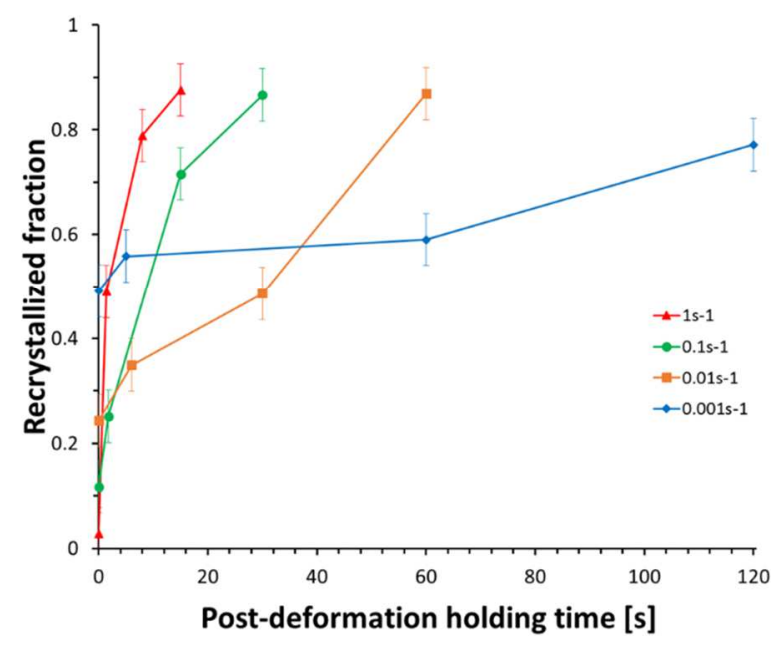

Figure $10:$ a) Increase in recrystallized fraction for different holding times before quenching after deformation. b) The same data are plotted as a function of time for each performed strain rate. These figures are built from samples whose KAM maps are presented on Figure 9.

\begin{tabular}{lcccc}
\hline Strain rate $\left[\mathrm{s}^{-1}\right]$ & 0.001 & 0.01 & 0.1 & 1 \\
\hline Mean GAKAM of deformed grains $\left[^{\circ}\right]$ & 0.83 & 0.96 & 1.42 & 1.01 \\
\hline Corresponding KAM maps on Figure 9 & $\mathrm{a}$ & $\mathrm{d}$ & $\mathrm{g}$ & $\mathrm{j}$ \\
\hline
\end{tabular}

Table 2: Mean GAKAM value of remaining deformed grains identified on samples water quenched right after deformation.

\begin{tabular}{lccc}
\hline Strain rate $\left[\mathrm{s}^{-1}\right]$ & 0.01 & 0.1 & 1 \\
\hline Holding time $[\mathrm{s}]$ & 60 & 30 & 15 \\
\hline Recrystallized fraction & 0.87 & 0.87 & 0.88 \\
\hline Mean GAKAM of deformed grains $\left[^{\circ}\right]$ & 0.50 & 0.60 & 0.45 \\
\hline Corresponding KAM maps on Figure 9 & $\mathrm{f}$ & $\mathrm{i}$ & 1 \\
\hline
\end{tabular}

Table 3: Comparison of mean GAKAM value of remaining deformed grains for samples with similar recrystallized volume fractions.

In addition, it can be observed here from Figures 9 and 10 for $\dot{\varepsilon} \geq 0.1 s^{-1}$ that the acceleration of PDRX kinetics is more pronounced in the very first moments following deformation. Then, for longer holding times, PDRX slows down. Such a slowdown of the PDRX kinetics for $\dot{\varepsilon} \geq 0.1 \mathrm{~s}^{-1}$ is typical of the end of PDRX [51] when most deformed grains have already been consumed, reducing the driving force for recrystallization. Nevertheless, for $\dot{\varepsilon} \geq 0.1 s^{-1}$, such a slowdown of PDRX kinetics could also be associated to the fact that the temperature is decreased compared to the one reached at the end of deformation.

As introduced in the beginning of this article, in the post-dynamic regime, both SRX and MDRX can contribute to the PDRX. Usually, MDRX and SRX differ by their kinetics. In opposition to MDRX, SRX is characterized by an incubation time before developing in the microstructure. Considering Figure 10b, the plateau obtained for PDRX kinetics at the lowest strain rate $\left(\dot{\varepsilon}=0.001 s^{-1}\right)$ strongly suggests that SRX is the main mechanism operating in 
post-dynamic regime. However, when $\dot{\varepsilon}=0.01 s^{-1}$, interpretation of PDRX kinetics is not as obvious, it is difficult to affirm that one mechanism is dominant over the other. Finally, given the very fast PDRX kinetics obtained after deformations at $\dot{\varepsilon} \geq 0.1 s^{-1}$, it is very unlikely that SRX would operate in those high strain rate conditions and PDRX seems to be controlled by MDRX.

Consistently with PDRX kinetics shown on Figure 10b for $\dot{\varepsilon} \geq 0.1 s^{-1}$, some MDRX grains (extended definition) can indeed be found qualitatively in microstructures as shown for example for grains A to F spotted on Figures $5 \mathbf{f}$ and 5j. Those grains contain both a strain hardened area (area with higher KAM values) corresponding to former DRX grains and an area free of strain hardening (area with lower KAM values) that corresponds to the volume swept by the grain boundary during PDRX. It can be mentioned here that the presence of this kind of grains in the microstructure slightly complicates the separation between DRX and PDRX grains for quantitative analyses. Depending on the respective proportion of strain hardened area (but also its strain hardening level) and hardening-free area composing MDRX grains, those grains are sometimes classified as DRX grains (grains A, B, C, D and F on Figure 5f and 5j) and sometimes as PDRX grains (grain E on Figure 5j). It is noticed here that PDRX grains without any strain hardened area (consistent with the definition of SRX grains) are also present in microstructures of Figure 5 (see white arrows for examples). The authors bring to the attention that it is not true to simply consider that these PDRX grains are SRX grains because of possible 2D section effects discussed in [42]. Indeed, they could also be MDRX grains with a DRX nucleus/grain out of the analysed surface.

\section{4. $\delta$ phase particles}

In this study, hot compression tests were performed at the nominal temperature $T=$ $980^{\circ} \mathrm{C}$. At such temperature, $\delta$ phase particles are present in the microstructure before deformation (see Figure $\mathbf{2 b}$ for the initial state). They then evolve and influence microstructure evolution during hot processing depending on the applied thermomechanical conditions and the equilibrium fraction which is estimated around $4 \%$ from results obtained by Beaubois et al. [52] for the same $\mathrm{Nb}$ content.

In the course of deformation, dislocations accumulation (so-called dislocations pillup) around $\delta$ particles has been observed in different studies addressing $\delta$-subsolvus processing of Inconel 718 [30, 53, 54]. This implies that those second phase particles induce modifications of the strain field at the intragranular scale, which is consistent with the fact that $\delta$ content impacts the flow stress behaviour as observed in [53]. As a result of a higher dislocation density found around $\delta$ particles, those ones can thus stimulate the DRX grains nucleation. This is the so-called Particles Stimulated Nucleation (PSN) which has ever been reported for Inconel 718 [30, 54]. On the other hand, it has also been demonstrated in the literature that second phase particles are able to pin grain boundaries. This so-called SmithZener pinning phenomenon exerted by $\delta$ phase particles on growing DRX grains in Inconel 718 has ever been reported $[55,56] . \delta$ phase particles undeniably interfere with recrystallization phenomena. The evolution of these particles is thus important to consider in this paper dedicated to recrystallization kinetics.

The $\delta$ phase precipitation state has been quantified on fast quenched samples (those used on Figure 5 for the determination of DRX kinetics). Figure 11 shows the $\delta$ phase volume fraction evolution as a function of strain rate for those samples compared to the initial 
state presented on Figure 2b. Each point represents the mean $\delta$ phase volume fraction obtained from ten backscattered electron images similar to those presented on Figure 12. In order to illustrate the graph of Figure 11, backscattered electron images of as quenched samples are shown for the lowest and the highest strain rates $\left(\dot{\varepsilon}=0.001 \mathrm{~s}^{-1}\right.$ and $\left.\dot{\varepsilon}=1 \mathrm{~s}^{-1}\right)$ on Figure 12b and 12c. Those ones can directly be compared to the one of initial microstructure (Figure 12a).

The $\delta$ phase evolution during deformation is drastically different depending on the strain rate. At low strain rate (typically here at $\dot{\varepsilon}=0.001 \mathrm{~s}^{-1}$ ), extensive dynamic precipitation of the $\delta$ phase is promoted (volume fraction increase from 0.5 to $1.5 \%$ ), and $\delta$ particles seem to be preferentially located along initial grain boundaries (see Figure 11 and 12b). At such low strain rate, compression test can be considered as isothermal and the long deformation time (more than 11 minutes) at $980^{\circ} \mathrm{C}$ allows dynamic precipitation of $\delta$ phase. In addition, the increase in dislocation density due to deformation is likely to accelerate the dynamic precipitation of the $\delta$ phase [57], especially in the first stages of deformation, when the mean dislocation density has not yet started to decrease due to DRX. Dislocations indeed accelerate diffusion. More specifically for Inconel 718 it has been reported in the literature that dislocations can boost diffusion of $\mathrm{Nb}$ atoms $[58,59]$ which are involved in the formation of $\delta$ phase. As a consequence, the $\delta$ phase content obtained after deformation at $\dot{\varepsilon}=0.001 s^{-1}$ is higher than the one resulting from a static heat treatment at $980^{\circ} \mathrm{C}$ for the same duration on initial state material (see Figure 11).

On the contrary, at high strain rate (typically here at $\dot{\varepsilon}=1 \mathrm{~s}^{-1}$ ), fast $\delta$ phase dissolution is observed. This fast dissolution of $\delta$ phase particles observed after high strain rate deformation implies a fast diffusion of $\mathrm{Nb}$ atoms from $\delta$ phase particles into the matrix. Temperature increase due to self-heating could be responsible of the fast diffusion of $\mathrm{Nb}$ atoms from $\delta$ phase particles into the matrix. As mentioned previously, high strain rate deformation induces significant self-heating, and so temperature during deformation and right after deformation could overpass the $\delta$ solvus temperature estimated here to be $T_{\delta} \approx 1040^{\circ} \mathrm{C}$ given the $\mathrm{Nb}$ content of the alloy [60]. Indeed, during high strain rate compression tests, deformation is not isothermal and performed tests are likely to move from subsolvus $\delta$ condition at the beginning of the deformation to supersolvus $\delta$ condition at the end of the deformation.

We have shown previously that recrystallized fraction identified on samples rapidly quenched after high strain rate deformation actually mostly comes from post-dynamic evolution. It sounds thus relevant to wonder if $\delta$ phase dissolution occurs during or after deformation. Given the short deformation times imposed by high strain rates, $\delta$ precipitate dissolution is likely to mainly occur after the deformation. Anyway, at high strain rate, whether the dissolution occurs during or after the deformation, the fact that there is a low amount of $\delta$ particles in the microstructure within the post-dynamic regime also very likely contributes to accelerate PDRX kinetics. 

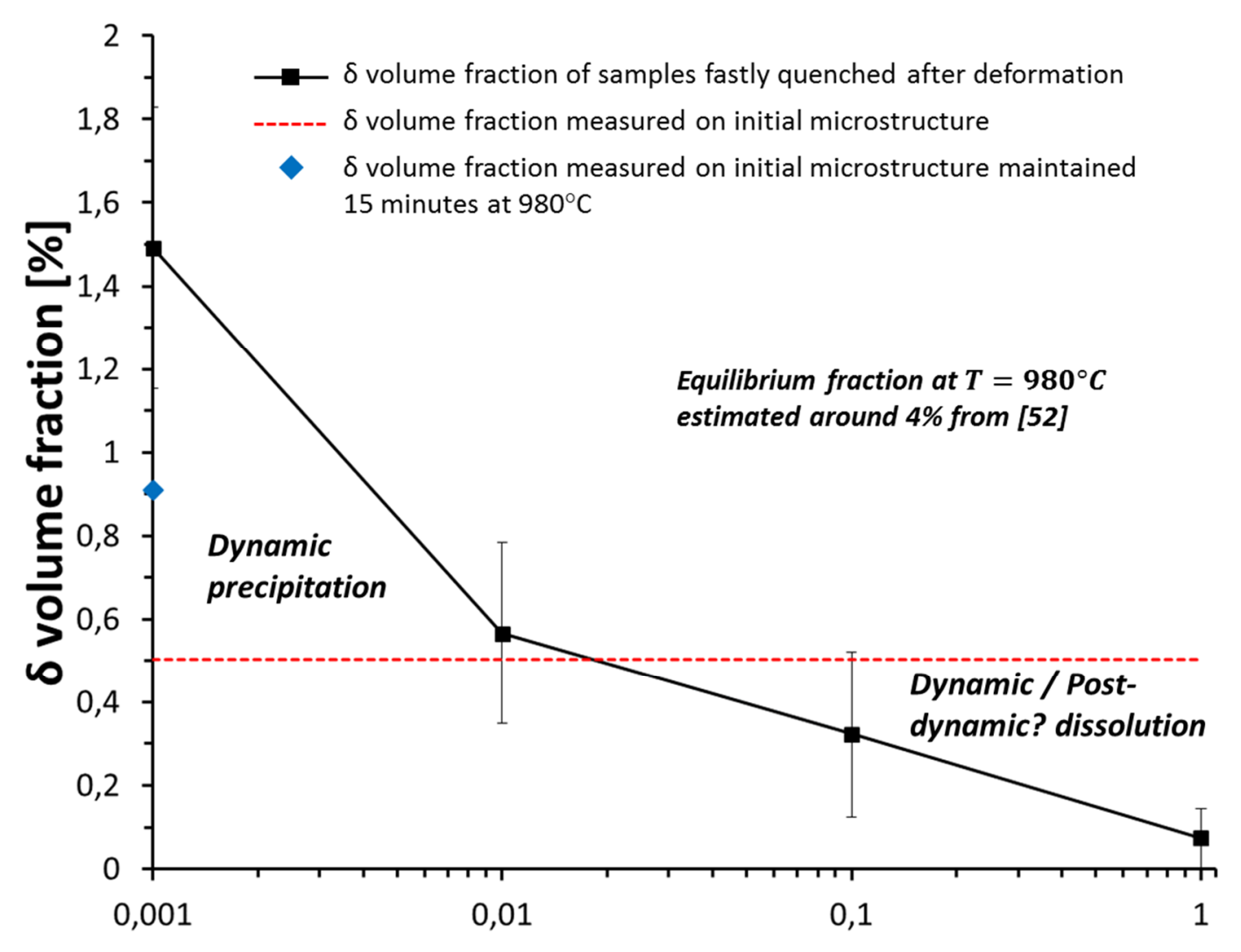

Strain rate $\left[\mathbf{s}^{-1}\right]$

Figure 11: $\delta$ phase volume fraction evolution as a function of strain rate for samples used for DRX kinetics characterization. Each point has been obtained from ten backscattered electron images, which represents a total analysed area of approximately $10^{5} \mathrm{\mu m}^{2}$. In this graph, vertical bars represent the standard deviation for each point. The dotted red line corresponds to the $\delta$ phase volume fraction measured on the initial state. The blue diamond corresponds to the $\delta$ phase volume fraction measured on the initial state after holding at $980^{\circ} \mathrm{C}$ for 15 minutes (slightly longer than the deformation time at $\dot{\varepsilon}=0.001 \mathrm{~s}^{-1}$ ).

a)

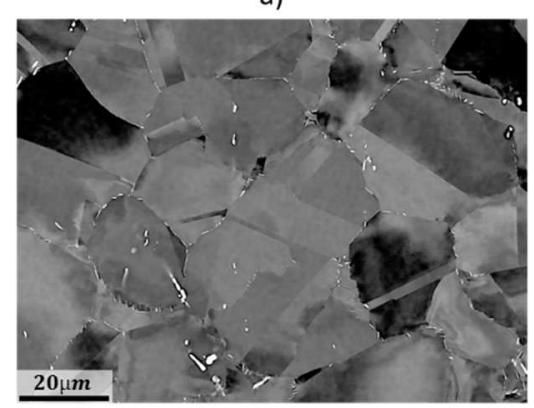

b)

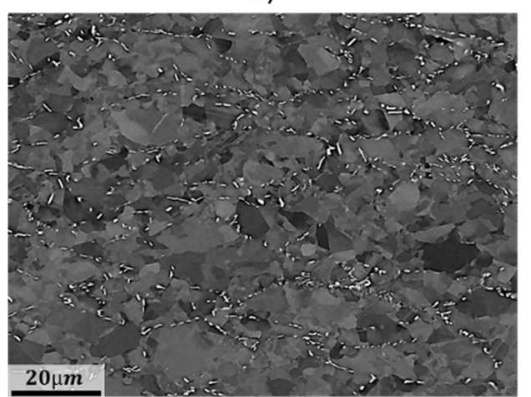

c)

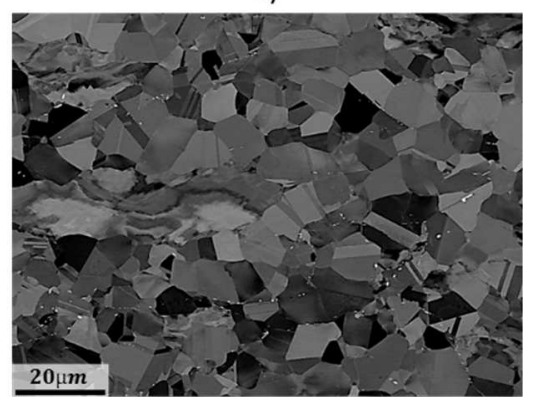

Figure 12: BSE images of a) Initial state, b) sample deformed at $\dot{\varepsilon}=0.001 \mathrm{~s}^{-1}$ and quenched right after deformation, c) sample deformed at $\dot{\varepsilon}=1 s^{-1}$ and quenched right after deformation. $\delta$ phase particles appear white owing to their average atomic number higher than that of the matrix. 


\section{Conclusions}

The strain rate influence on DRX and PDRX kinetics was investigated by performing compression tests at strain rates in the range $[0.001 ; 1] s^{-1}$. A new approach was used for the separation between DRX and PDRX grains for the establishment of DRX and PDRX kinetics, based on the analysis of intragranular misorientations in EBSD maps with enhanced angular resolution. From this study, several important results have been demonstrated:

- For the Inconel 718 alloy deformed at $980^{\circ} \mathrm{C}$, the DRX is inhibited at high strain rate, mostly due to short deformation time, when the strain rate is increased above $0.1 \mathrm{~s}^{-1}$. The critical strain rate massively reported in literature and illustrated on Figure 1, above which the DRX kinetics would on the contrary be accelerated, does actually not exist under the applied conditions.

- On the other hand, PDRX kinetics is drastically accelerated after high strain rate deformation $\left(>0.1 \mathrm{~s}^{-1}\right)$. Self-heating inherent to high strain rate deformation has been identified to be the main feature contributing to PDRX kinetics acceleration. The fast dissolution of $\delta$ phase particles is also observed during and/or after high strain rate deformation, mainly associated with selfheating as well, and may also contribute to PDRX acceleration.

- The classical approach for the estimation of DRX kinetics where the DRX fraction is assimilated to the total recrystallized fraction measured in samples quenched right after deformation is no longer adapted for high strain rate deformation (from $\dot{\varepsilon} \geq 0.1 s^{-1}$ under the conditions applied in this study). Indeed, at high strain rate, the characteristic time for PDRX becomes comparable or shorter than the minimum quenching delay which is technically achievable.

- Accelerated PDRX kinetics after high strain rate deformations is very likely to be responsible of the differences observed between DRX kinetics as a function of strain rate presented in this study and those reported in the literature.

- Discussion of DRX initiation based on stress-strain curves and so-called stress-peaks is no longer relevant for high strain rate deformation due to the effect of self-heating on stress levels.

- For a given temperature and a given strain level, strain rate could be determinant for mechanical properties as well. Indeed, recrystallized grains after hot deformation at low strain rate are mainly strain hardened DRX grains while recrystallized grains obtained after hot deformation at high strain rate are mainly PDRX grains with much lower dislocation densities. This is likely to affect mechanical properties since DRX grains are strain hardened contrary PDRX grains and since dislocation density may also impact the precipitation of hardening phases (mainly $\gamma^{\prime \prime}$ in the Inconel 718 alloy).

\section{Acknowledgments}

The work received the financial support from the French Agency for Scientific Research (ANR) and from the Safran group via the industrial chair ANR-Safran OPALE. 


\section{References}

[1] D. Texier, A.C. Gómez, S. Pierret, J.M. Franchet, T.M. Pollock, P. Villechaise, J. Cormier, Microstructural Features Controlling the Variability in Low-Cycle Fatigue Properties of Alloy Inconel 718DA at Intermediate Temperature, Metall. Mater. Trans. A. 47 (2016) 1096-1109.

[2] M. Azarbarmas, M. Aghaie-Khafri, J.M. Cabrera, J. Calvo, Dynamic recrystallization mechanisms and twining evolution during hot deformation of Inconel 718, Mater. Sci. Eng. A. 678 (2016) 137-152.

[3] Y.C. Lin, X.Y. Wu, X.M. Chen, J. Chen, D.X. Wen, J.L. Zhang, L.T. Li, EBSD study of a hot deformed nickel-based superalloy, J. Alloys Compd. 640 (2015) 101-113.

[4] Y. Wang, W.Z. Shao, L. Zhen, L. Yang, X.M. Zhang, Flow behavior and microstructures of superalloy 718 during high temperature deformation, Mater. Sci. Eng. A. 497 (2008) 479-486.

[5] P. Pöelt, C. Sommitsch, S. Mitsche, M. Walter, Dynamic recrystallization of Ni-base alloys-Experimental results and comparisons with simulations, Mater. Sci. Eng. A. 420 (2006) 306-314.

[6] T.S. Prithiv, P. Bhuyan, S.K. Pradhan, V. Subramanya Sarma, S. Mandal, A critical evaluation on efficacy of recrystallization vs. strain induced boundary migration in achieving grain boundary engineered microstructure in a Ni-base superalloy, Acta Mater. 146 (2018) 187-201.

[7] N. Bozzolo, N. Souaï, R.E. Logé, Evolution of microstructure and twin density during thermomechanical processing in a $\gamma-\gamma$ ' nickel-based superalloy, Acta Mater. 60 (2012) 5056-5066.

[8] M. Pérez, C. Dumont, O. Nodin, S. Nouveau, Impact of forging direction on the recrystallization behaviour of nickel base superalloy AD730 billet material at subsolvus temperatures, Mater. Charact. 146 (2018) 169-181.

[9] G. He, F. Liu, L. Huang, Z. Huang, L. Jiang, Controlling grain size via dynamic recrystallization in an advanced polycrystalline nickel base superalloy, J. Alloys Compd. 701 (2017) 909-919.

[10] Y. Liu, Z. Yao, Y. Ning, Y. Nan, Effect of deformation temperature and strain rate on dynamic recrystallized grain size of a powder metallurgical nickel-based superalloy, J. Alloys Compd. 691 (2017) 554-563.

[11] M.A. Charpagne, T. Billot, J.M. Franchet, N. Bozzolo, Heteroepitaxial recrystallization: A new mechanism discovered in a polycrystalline $\gamma-\gamma^{\prime}$ nickel based superalloy, J. Alloys Compd. 688 (2016) 685-694.

[12] M.J. Lutont, C.M. Sellars, Dynamic recrystallization in nickel-iron alloys during high temperature deformation, Acta Metall. 44 (1996) 127-136.

[13] E.I. Poliak, J.J. Jonass, A one-parameter approach to determining the critical conditions for the initiation of dynamic recrystallization, Acta Mater. 44 (1996) 127-136.

[14] T. Sakai, J.J. Jonas, Overview no. 35 Dynamic recrystallization: Mechanical and 
microstructural considerations, Acta Metall. 32 (1984) 189-209.

[15] T. Sakai, A. Belyakov, R. Kaibyshev, H. Miura, J.J. Jonas, Dynamic and post-dynamic recrystallization under hot, cold and severe plastic deformation conditions, Prog. Mater. Sci. 60 (2014) 130-207.

[16] D. Raabe, Recovery and Recrystallization: Phenomena, Physics, Models, Simulation, in: Physical Metallurgy, Fifth edition, 2014, pp. 2291-2397.

[17] J. Humphreys, G.S. Rohrer, A. Rollett, J. Humphreys, G.S. Rohrer, A. Rollett, Chapter 13 - Hot Deformation and Dynamic Restoration, in: Recrystallization and Related Annealing Phenomena, Third edition, 2017, pp. 469-508.

[18] A. Manonukul, F.P.. Dunne, Initiation of dynamic recrystallization under inhomogeneous stress states in pure copper, Acta Mater. 47 (1999) 4339-4354.

[19] S.M. Fatemi-Varzaneh, A. Zarei-Hanzaki, H. Beladi, Dynamic recrystallization in AZ31 magnesium alloy, Mater. Sci. Eng. A. 456 (2007) 52-57.

[20] H. Beladi, P. Cizek, P.D. Hodgson, Dynamic Recrystallization of Austenite in Ni-30 Pct Fe Model Alloy: Microstructure and Texture Evolution, Metall. Mater. Trans. A. 40 (2009) 1175-1189.

[21] Y. Xu, C. Chen, X. Zhang, H. Dai, J. Jia, Z. Bai, Dynamic recrystallization kinetics and microstructure evolution of an AZ91D magnesium alloy during hot compression, Mater. Charact. 145 (2018) 39-52.

[22] R.P. Guest, S. Tin, The Dynamic and Metadynamic Recrystallisation of IN 718, in: Proceedings of the International Symposium on Superalloys and Various Derivatives, 2005, pp. 373-383.

[23] Y.S. Na, J.T. Yeom, N.K. Park, J.Y. Lee, Simulation of microstructures for Alloy 718 blade forging using 3D FEM simulator, J. Mater. Process. Technol. 141 (2003) 337342 .

[24] D.G. He, Y.C. Lin, M.S. Chen, L. Li, Kinetics equations and microstructural evolution during metadynamic recrystallization in a nickel-based superalloy with $\delta$ phase, J. Alloys Compd. 690 (2017) 971-978.

[25] Y.C. Lin, X.M. Chen, M.S. Chen, Y. Zhou, D.X. Wen, D.G. He, A new method to predict the metadynamic recrystallization behavior in a typical nickel-based superalloy, Appl. Phys. A. 122 (2016) 601.

[26] M. Zouari, R.E. Logé, N. Bozzolo, In Situ Characterization of Inconel 718 PostDynamic Recrystallization within a Scanning Electron Microscope, Metals 7 (2017) 476.

[27] Y. Wang, W.Z. Shao, L. Zhen, X.M. Zhang, Microstructure evolution during dynamic recrystallization of hot deformed superalloy 718, Mater. Sci. Eng. A. 486 (2008) 321332.

[28] N.K. Park, I.S. Kim, Y.S. Na, J.T. Yeom, Hot forging of a nickel-base superalloy, J. Mater. Process. Technol. 111 (2001) 98-102.

[29] L.X. Zhou, T.N. Baker, Effects of strain rate and temperature on deformation behaviour of IN 718 during high temperature deformation, Mater. Sci. Eng. A 177 (1994) 1-9. 
[30] Y.C. Lin, D.G. He, M.S. Chen, X.M. Chen, C.Y. Zhao, X. Ma, Z.L. Long, EBSD analysis of evolution of dynamic recrystallization grains and $\delta$ phase in a nickel-based superalloy during hot compressive deformation, Mater. Des. 97 (2016) 13-24.

[31] D. Jia, W. Sun, D. Xu, L. Yu, X. Xin, W. Zhang, F. Qi, Abnormal dynamic recrystallization behavior of a nickel based superalloy during hot deformation, J. Alloys Compd. 787 (2019) 196-205.

[32] D. Zhao, P.K. Chaudhury, Effect of Starting Grain Size on As-Deformed Microstructure in High Temperature Deformation of Alloy 718, Superalloys 718, 625, 706 Var. Deriv. (1994) 303-313.

[33] M. Azarbarmas, M. Aghaie-Khafri, J.M. Cabrera, J. Calvo, Microstructural evolution and constitutive equations of Inconel 718 alloy under quasi-static and quasi-dynamic conditions, Mater. Des. 94 (2016) 28-38.

[34] H. Zhang, K. Zhang, H. Zhou, Z. Lu, C. Zhao, X. Yang, Effect of strain rate on microstructure evolution of a nickel-based superalloy during hot deformation, Mater. Des. 80 (2015) 51-62.

[35] S.S.S. Kumar, T. Raghu, P.P. Bhattacharjee, G.A. Rao, U. Borah, Strain rate dependent microstructural evolution during hot deformation of a hot isostatically processed nickel base superalloy, J. Alloys Compd. 681 (2016) 28-42.

[36] H. Jiang, J. Dong, M. Zhang, Z. Yao, A Study on the Effect of Strain Rate on the Dynamic Recrystallization Mechanism of Alloy 617B, Metall. Mater. Trans. A. 47 (2016) 5071-5087.

[37] N.R. Jaladurgam, A.K. Kanjarla, Hot deformation characteristics and microstructure evolution of Hastelloy C-276, Mater. Sci. Eng. A. 712 (2018) 240-254.

[38] Z. Shi, X. Yan, C. Duan, M. Zhao, Effect of strain rate on hot deformation characteristics of GH690 superalloy, Trans. Nonferrous Met. Soc. China. 27 (2017) $538-550$.

[39] Y. Fang, X. Chen, B. Madigan, H. Cao, S. Konovalov, Effects of strain rate on the hot deformation behavior and dynamic recrystallization in China low activation martensitic steel, Fusion Eng. Des. 103 (2016) 21-30.

[40] S. Mandal, A.K. Bhaduri, V.S. Sarma, Role of twinning on dynamic recrystallization and microstructure during moderate to high strain rate hot deformation of a Timodified austenitic stainless steel, Metall. Mater. Trans. A. 43 (2012) 2056-2068.

[41] Y. Cao, H. Di, J. Zhang, J. Zhang, T. Ma, R.D.K. Misra, An electron backscattered diffraction study on the dynamic recrystallization behavior of a nickel-chromium alloy $(800 \mathrm{H})$ during hot deformation, Mater. Sci. Eng. A. 585 (2013) 71-85.

[42] A. Nicolaÿ, J.M. Franchet, J. Cormier, H. Mansour, M. De Graef, A. Seret, N. Bozzolo, Discrimination of dynamically and post-dynamically recrystallized grains based on EBSD data: application to Inconel 718, J. Microsc. 273 (2019) 135-147.

[43] F. Bachmann, R. Hielscher, H. Schaeben, Grain detection from 2d and 3d EBSD data-Specification of the MTEX algorithm, Ultramicroscopy. 111 (2011) 1720-1733.

[44] C. Moussa, M. Bernacki, R. Besnard, N. Bozzolo, Statistical analysis of dislocations and dislocation boundaries from EBSD data, Ultramicroscopy. 179 (2017) 63-72. 
[45] A. Seret, C. Moussa, M. Bernacki, R. Signorelli, N. Bozzolo, Estimation of geometrically necessary dislocation density from filtered EBSD data by a local linear adaptation of smoothing splines, accepted in J. Appl. Crystallogr.

[46] G. Camus, B. Pieraggi, F. Chevet, Hot Deformation and Recrystallization of Inconel 718, Formability Metall. Struct. (1986) 305-325.

[47] C. Kienl, A. Casanova, O.M.D.M. Messé, C. Argyrakis, C.M.F. Rae, Characterization of the Initial Stages of Dynamic Recrystallization in ATI 718Plus ${ }^{\circledR}$, in: Proceedings of the $9^{\text {th }}$ International Symposium on superalloy 718 \& Derivates, 2018, pp. 405-420.

[48] U.F. Kocks, H. Mecking, Physics and phenomenology of strain hardening: the FCC case, Prog. Mater. Sci. 48 (2003) 171-273.

[49] D. Huber, C. Stotter, C. Sommitsch, S. Mitsche, P. Pöelt, B. Buchmayr, M. Stockinger, Microstructure Modeling of the Dynamic Recrystallization Kinetics during Turbine Disc Forging of the Nickel Based Superalloy Allvac 718 Plus, in: Proceedings of the $11^{\text {th }}$ International Symposium on Superalloys, 2008, pp. 855-861.

[50] J. Zhang, H. Di, X. Wang, Y. Cao, J. Zhang, T. Ma, Constitutive analysis of the hot deformation behavior of Fe-23Mn-2Al-0.2C twinning induced plasticity steel in consideration of strain, Mater. Des. 44 (2013) 354-364.

[51] M. Zouari, N. Bozzolo, R.E. Loge, Mean field modelling of dynamic and post-dynamic recrystallization during hot deformation of Inconel 718 in the absence of $\delta$ phase particles, Mater. Sci. Eng. A. 655 (2016) 408-424.

[52] V. Beaubois, J. Huez, S. Coste, O. Brucelle, J. Lacaze, Short term precipitation kinetics of delta phase in strain free Inconel* 718 alloy, Mater. Sci. Technol. 20 (2004) 10191026.

[53] D.X. Wen, Y.C. Lin, X.H. Li, S.K. Singh, Hot deformation characteristics and dislocation substructure evolution of a nickel-base alloy considering effects of $\delta$ phase, J. Alloys Compd. 764 (2018) 1008-1020.

[54] Y. Wang, L. Zhen, W.Z. Shao, L. Yang, X.M. Zhang, Hot working characteristics and dynamic recrystallization of delta-processed superalloy 718, J. Alloys Compd. 474 (2009) 341-346.

[55] M. Cheng, H.Y. Zhang, S.H. Zhang, Microstructure evolution of delta-processed IN718 during holding period after hot deformation, J. Mater. Sci. 47 (2012) 251-256.

[56] J. Humphreys, G.S. Rohrer, A. Rollett, J. Humphreys, G.S. Rohrer, A. Rollett, Chapter 4 - The Structure and Energy of Grain Boundaries, in: Recrystallization and Related Annealing Phenomena, 2017, pp. 109-143.

[57] Y. Mei, Y. Liu, C. Liu, C. Li, L. Yu, Q. Guo, H. Li, Effects of cold rolling on the precipitation kinetics and the morphology evolution of intermediate phases in Inconel 718 alloy, (2015).

[58] D.G. He, Y.C. Lin, X.Y. Jiang, L.X. Yin, L.H. Wang, Q. Wu, Dissolution mechanisms and kinetics of $\delta$ phase in an aged Ni-based superalloy in hot deformation process, Mater. Des. 156 (2018) 262-271.

[59] Y. Wang, W.Z. Shao, L. Zhen, B.Y. Zhang, Hot deformation behavior of deltaprocessed superalloy 718, Mater. Sci. Eng. A. 528 (2011) 3218-3227. 
[60] A. Niang, B. Viguier, J. Lacaze, Some features of anisothermal solid-state transformations in alloy 718, Mater. Charact. 61 (2010) 525-534. 

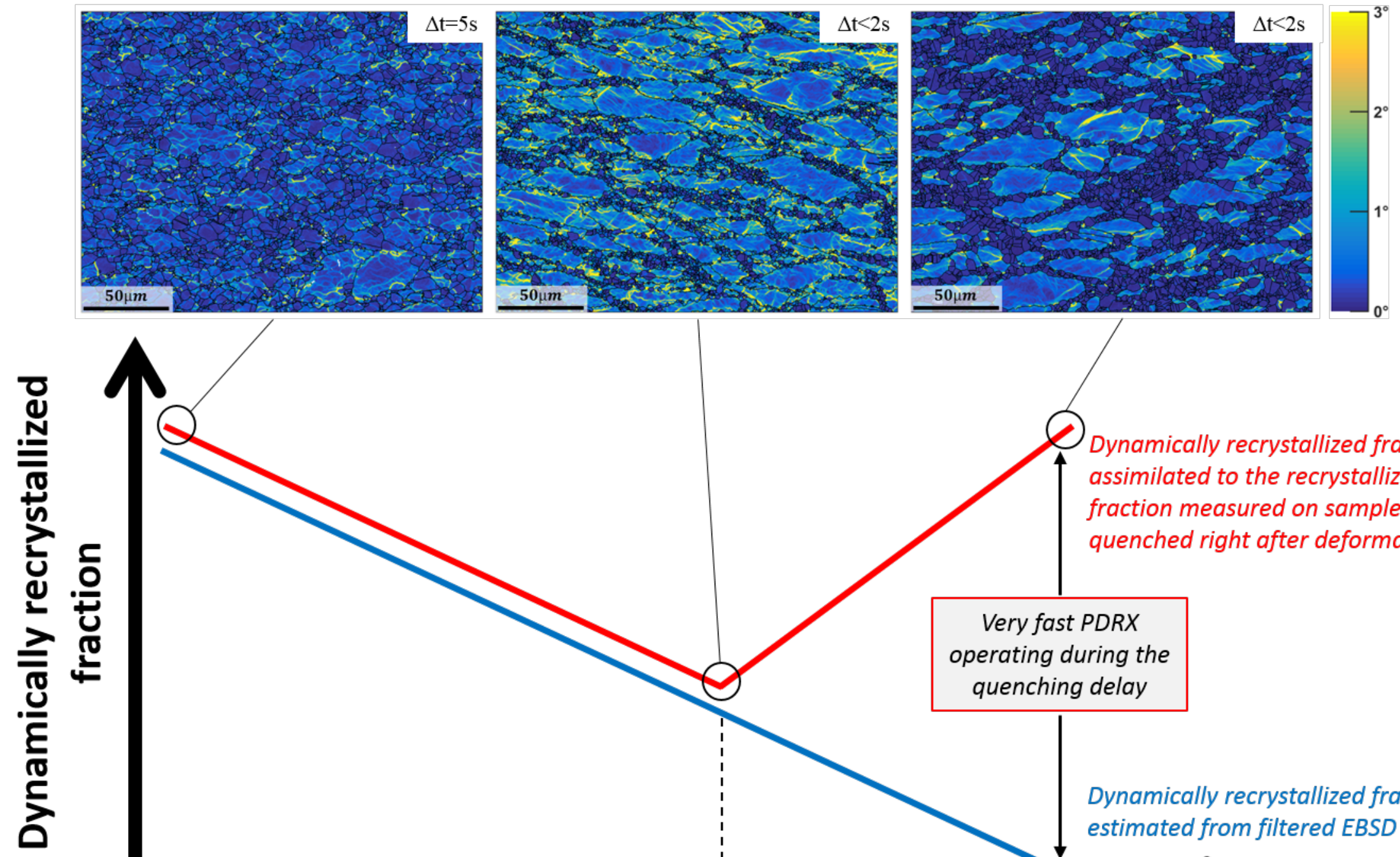

$\uparrow$

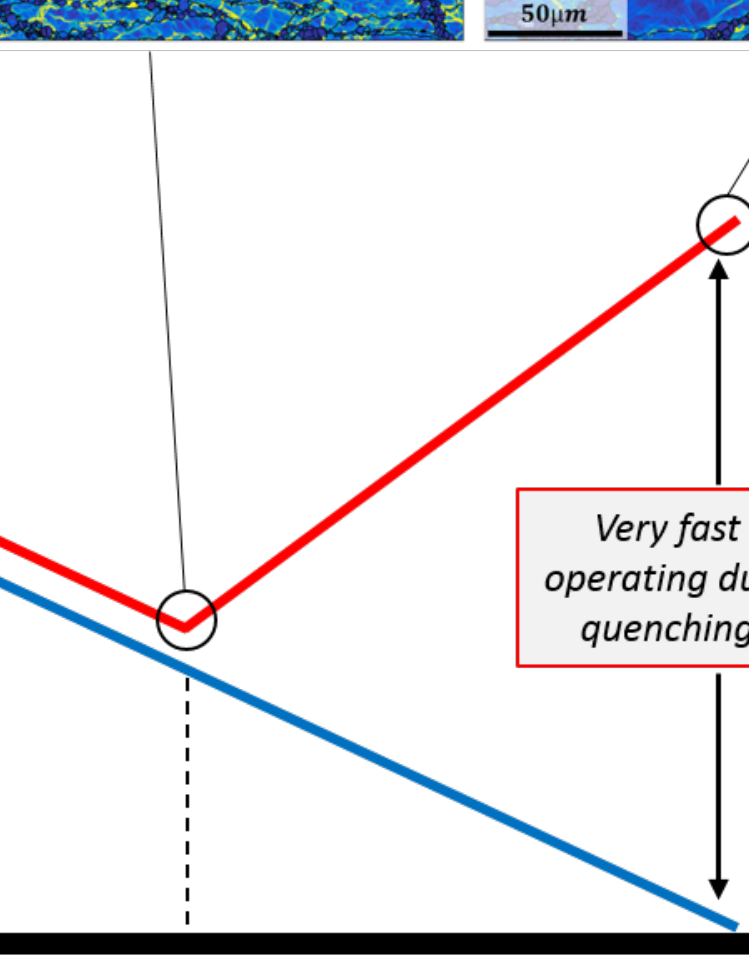

Dynamically recrystallized fraction assimilated to the recrystallized fraction measured on samples water quenched right after deformation

Dynamically recrystallized fraction estimated from filtered EBSD data 